\title{
EXAFS Study on the Coordination Chemistry of the Solvated Copper(II) Ion in a Series of Oxygen Donor Solvents
}

\author{
Ingmar Persson,* Daniel Lundberg, Éva G. Bajnóczi, Konstantin Klementiev, Justus Just, \\ and Kajsa G. V. Sigfridsson Clauss
}

Cite This: Inorg. Chem. 2020, 59, 9538-9550

Read Online

ACCESS | Llll Metrics \& More | 国 Article Recommendations | sl Supporting Information

ABSTRACT: The structures of the solvated copper(II) ion in water and nine organic oxygen donor solvents with similar electron-pair donor ability, but with different space-demanding properties at coordination, have been studied by EXAFS. $N, N^{\prime}$-Dimethylpropyleneurea and $N, N, N^{\prime}, N^{\prime}$-tetramethylurea are sufficiently space demanding at coordination to make the axial positions not accessible, resulting in square-planar copper(II) solvate complexes with an intense green color. The mean $\mathrm{Cu}-\mathrm{O}$ bond distances in these two solvate complexes are $1.939(3)$ and 1.935(3) A, respectively. The best fits of the remaining solvates, which are light blue in different hues, are obtained with a Jahn-Teller distorted-octahedral model consisting of four strongly bound solvent molecules in the equatorial positions at 1.96(2) $\AA$ and two in the axial positions but with different $\mathrm{Cu}-\mathrm{O}_{\mathrm{ax}}$ bond distances: ca. 2.15 and $2.32 \AA$. This is in agreement with observations in solid-state structures of compounds containing hexaaquacopper(II) complexes crystallizing in noncentrosymmetric space groups and all reported crystal structures containing a $\left[\mathrm{Cu}\left(\mathrm{H}_{2} \mathrm{O}\right)_{5}(\mathrm{O}\right.$-ligand) $]$ complex with Jahn-Teller distortion. Such a structure is in agreement with previous EPR and EXAFS studies proving

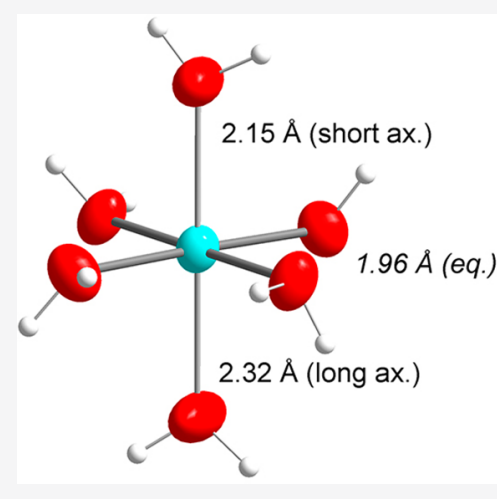
the hydrated copper(II) ion to be a noncentrosymmetric complex in aqueous solution. The refinements of the EXAFS data of the solids $\left[\mathrm{Cu}\left(\mathrm{H}_{2} \mathrm{O}\right)_{6}\right]\left(\mathrm{ClO}_{4}\right)_{2},\left[\mathrm{Cu}\left(\mathrm{H}_{2} \mathrm{O}\right)_{6}\right]\left(\mathrm{BrO}_{3}\right)_{2},\left[\mathrm{Cu}\left(\mathrm{H}_{2} \mathrm{O}\right)_{6}\right] \mathrm{SiF}_{6}, \mathrm{Cu}\left(\mathrm{NO}_{3}\right)_{2} \cdot 2.5 \mathrm{H}_{2} \mathrm{O}$, and $\mathrm{CuSO} \mathrm{O}_{4} \cdot 5 \mathrm{H}_{2} \mathrm{O}$ gave $\mathrm{Cu}-\mathrm{O}$ bond distances significantly different from those reported in the crystallographic studies but similar to the configuration and bond distances in the hydrated copper(II) ion in aqueous solution. This may depend on whether the orientation of the axial positions is random in one or three dimensions, giving a mean structure of the solid with symmetry higher than that of the individual complexes. This study presents the very first experimental data from the new X-ray absorption spectroscopy beamline Balder at the MAX IV synchrotron radiation facility in Lund, Sweden, as well as the utilized properties of the beamline.

\section{INTRODUCTION}

The most debated hydrated metal ion by far in recent years is copper(II). It was assumed for a long time that the hydrated copper(II) ion is six-coordinate with a tetragonally elongated octahedral configuration along a 4-fold axis, known as JahnTeller distortion, ${ }^{1-3}$ in aqueous solution. It can be concluded that a majority of the solid compounds containing a hydrated copper(II) ion have this configuration ${ }^{4,5}$ (Table S1). This has led many to believe that the same structure is also present in aqueous solution, even though a structure of a metal complex in the solid state cannot be related to its structure in solution. ${ }^{6}$ Linear electric field EPR studies gave the first indications that the hydrated copper(II) ion in aqueous solution was not centrosymmetric, as required by a regular Jahn-Teller distorted octahedron. ${ }^{7,8}$ A combined neutron scattering and molecular dynamics study proposed that the hydrated copper(II) ion is five-coordinate in aqueous solution. ${ }^{9}$ This study was followed a by series of publications using EXAFS and XANES spectroscopy, X-ray and neutron scattering on liquids, and DFT and QM/MD simulations on different levels to study the coordination chemistry of the hydrated copper(II) ion in aqueous solution. ${ }^{10-25}$ A majority of these studies propose a tetragonally elongated square-pyramidal configuration as the most likely or stable structure, $9,10,13,15,16,25$ but several studies have proposed dynamic equilibria among four-, five-, and/or six-coordinated hydrate complexes, ${ }^{14,19,20,22,23}$ as well as a six-coordinate Jahn-Teller distorted-octahedral configuration. ${ }^{11,12,18,21}$ This shows that the discussion of the structure of the hydrated copper(II) ion aqueous solution is still a matter of debate.

The most extensive experimental studies have been performed by Frank and co-workers, who in a series of studies have applied XANES and high- $k$ EXAFS spectroscopy on both aqueous solutions and frozen samples of the hydrated copper(II) ion. ${ }^{13,22,25}$ They have applied three basic models:

Received: February 11, 2020

Published: July 2, 2020 
five-coordination in a tetragonally elongated square-pyramidal configuration and six-coordination in Jahn-Teller distortedoctahedral configurations with equal (centrosymmetric) and different $\mathrm{Cu}-\mathrm{O}$ bond distances in the axial positions (noncentrosymmetric). The EXAFS data of an aqueous copper(II) solution were fitted equally well with squarepyramidal and noncentrosymmetric Jahn-Teller distortedoctahedral models, with $\mathrm{Cu}-\mathrm{O}$ bond distances of 1.97 and $2.21 \AA$ and of $1.97,2.19$, and $2.33 \AA$, respectively. ${ }^{22}$ On the other hand, in the refinement of XANES data using the MXAN program, the best fit was obtained with a square-pyramidal model with $\mathrm{Cu}-\mathrm{O}$ bond distances of 1.95 and $2.23 \AA^{22}$ Studies on frozen samples of 1,3-propanediol and 1,5pentanediol aqueous glasses revealed asymmetric six-coordination with $\mathrm{Cu}-\mathrm{O}_{\mathrm{eq}}, \mathrm{Cu}-\mathrm{O}_{\mathrm{ax} 1}$, and $\mathrm{Cu}-\mathrm{O}_{\mathrm{ax} 2}$ bond distances of $4 \times 1.94,2.22$, and $2.34 \AA$, respectively, from EXAFS data, while MXAN data revealed copper sites with two kinds of sixcoordination, asymmetric Jahn-Teller distorted-octahedral (4 $\times 1.94,1 \times 2.14$, and $2.28 \AA$ ) and capped-square-pyramidal configurations $(5 \times 1.94$ and $2.22 \AA)$, and five-coordinated sites in a square-pyramidal configuration $(4 \times 1.95$ and 2.23 $\AA$ ). ${ }^{25}$ D'Angelo and co-workers have studied the solvated copper(II) ion methanol, dimethyl sulfoxide and acetontrile solution by combined XANES and EXAFS, showing that tetragonally elongated square-pyramidal coordination is preferred in these solvents. $^{26,27}$

It is important to emphasize that techniques such as EXAFS and XANES spectroscopy cannot give an absolute answer about the structure, as several models may fit the experimental data equally or almost equally well and the starting model may affect the outcome of the refinement. It is therefore important to test as many reasonable structure models as possible. Calculations have shown that the energy barrier between centrosymmetric Jahn-Teller distorted $\left[\mathrm{Cu}\left(\mathrm{H}_{2} \mathrm{O}\right)_{4}\left(\mathrm{H}_{2} \mathrm{O}\right)_{2}\right]^{2+}$ and noncentrosymmetric $\left[\mathrm{Cu}\left(\mathrm{H}_{2} \mathrm{O}\right)_{4}\left(\mathrm{H}_{2} \mathrm{O}\right)\left(\mathrm{H}_{2} \mathrm{O}\right)\right]^{2+}$ is small, $-82 \mathrm{meV}\left(-7.95 \mathrm{~kJ} \mathrm{~mol}^{-1}\right){ }^{17}$ Independent QMCF/MD molecular dynamics calculations did observe this delicate energy balance, resulting in a mean equilibrium geometry with $\mathrm{Cu}-\mathrm{O}$ bond distances of $4 \times 2.03,2.15$, and $2.30 \AA$ and $4 \times$ 2.07 and $2 \times 2.2 \AA$ including and excluding the second hydration shell into the QM zone, respectively, and a B3LYP/ MM simulation, $4 \times 2.02$ and $2 \times 2.29 \AA^{11,12}$

In order to give another perspective on this debate, a survey and analysis of reported solid-state structures containing four-, five-, and six-coordinate copper(II) hydrates and other copper(II) complexes with oxygen donor ligands are presented in this study. Of these structures, a large majority have a JahnTeller distorted-octahedral geometry around copper(II). Of the 139 reported crystal structures containing a $\left[\mathrm{Cu}\left(\mathrm{H}_{2} \mathrm{O}\right)_{6}\right]^{2+}$ ion, 105 report a regular Jahn-Teller distorted configuration with pairwise equal $\mathrm{Cu}-\mathrm{O}$ bond distances due to symmetry rules of the space groups. The mean $\mathrm{Cu}-\mathrm{O}_{\mathrm{eq}}$ and $\mathrm{Cu}-\mathrm{O}_{\mathrm{ax}}$ bond distances in these structures are 1.981 and $2.332 \AA$, respectively (Table $\mathrm{S} 1$ ). Two structures containing a $[\mathrm{Cu}-$ $\left.\left(\mathrm{H}_{2} \mathrm{O}\right)_{6}\right]^{2+}$ ion crystallize in a centrosymmetric space group, but the copper in the $\left[\mathrm{Cu}\left(\mathrm{H}_{2} \mathrm{O}\right)_{6}\right]^{2+}$ ion is not in the center of symmetry, $^{28,29}$ and another five structures crystallize in noncentrosymmetric space groups..$^{30-33}$ In these seven structures the axial $\mathrm{Cu}-\mathrm{O}$ bond distances are significantly different with mean distances of 2.298 and $2.362 \AA$ (Table S1). A limited number of the hexaaquacopper(II) complexes are reported to have regular or slightly irregular octahedral configurations: 7 and 21, respectively (Table S1).
To further check whether there are more examples showing a significant difference in the $\mathrm{Cu}-\mathrm{O}_{\mathrm{ax}}$ bond distances, crystal structures containing complexes with the composition $[\mathrm{Cu}$ $\left(\mathrm{H}_{2} \mathrm{O}\right)_{5} \mathrm{O}^{\prime}$ ], where $\mathrm{O}^{\prime}$ is a monodentate oxygen donor ligand, with reported Jahn-Teller distortion were summarized, as such complexes cannot individually be centrosymmetric. Indeed, all of these structures display significantly different $\mathrm{Cu}-\mathrm{O}_{\mathrm{ax}}$ bond distances (Table S2), and they all have similar $\mathrm{Cu}-\mathrm{O}$ bond distances in the equatorial positions independent of whether the $\mathrm{O}^{\prime}$ ligand binds in an equatorial or an axial position. Four of these structures have water molecules in the axial positions, and the difference in $\mathrm{Cu}-\mathrm{O}_{\mathrm{ax}}$ bond distance is $0.07-0.43 \AA$, and a similar pattern is seen in the compounds with the $\mathrm{O}^{\prime}$ ligand in the axial position (Table S2).

A possible reason as to why a majority of the structures with hexaaquacopper(II) ions crystallize in centrosymmetric space groups is that the direction of possibly different $\mathrm{Cu}-\mathrm{O}_{\mathrm{ax}}$ bond distances is randomly distributed in the structure. The mean structure, from a crystallographic point of view, becomes centrosymmetric with identical $\mathrm{Cu}-\mathrm{O}_{\mathrm{ax}}$ bond distances. This is certainly also the case for the 28 crystal structures reporting an apparent regular or a slightly distorted octahedral $[\mathrm{Cu}-$ $\left.\left(\mathrm{H}_{2} \mathrm{O}\right)_{6}\right]^{2+}$ complex, but here the random orientation of the axial positions is distributed in three dimensions (Table S1). When the orientation of the axial positions is randomly distributed in the structure, the mean structure has a higher symmetry in comparison to the individual complexes, and the observed space group is thereby allowed to have higher symmetry in comparison to the individual complexes. By using a lattice-independent structure method such as EXAFS the distances to the absorbing atom are independent of orientation in space, giving the actual distance distribution. A previous EXAFS study has shown that the crystal structures of $\left[\mathrm{Cu}\left(\mathrm{H}_{2} \mathrm{O}\right)_{6}\right]\left(\mathrm{BrO}_{3}\right)_{2}$ and $\left[\mathrm{Cu}\left(\mathrm{H}_{2} \mathrm{O}\right)_{6}\right] \mathrm{SiF}_{6}$, and some other six-coordinate homoleptic copper(II) complexes displaying regular octahedral geometry, actually have a distorted geometry with two well-separated distances. ${ }^{34}$ This "too high symmetry" effect has been also seen in e.g. the crystal structures of $\left[\mathrm{Sc}\left(\mathrm{H}_{2} \mathrm{O}\right)_{8.0}\right]\left(\mathrm{CF}_{3} \mathrm{SO}_{3}\right)_{3}$ and $\left[\mathrm{Lu}\left(\mathrm{H}_{2} \mathrm{O}\right)_{8.2}\right]$ $\left(\mathrm{CF}_{3} \mathrm{SO}_{3}\right)_{3} \cdot{ }^{35,36}$ In these two cases, a phase transition to lower symmetry takes place on cooling and the true structure is observed in the low-temperature phases. EXAFS studies have shown that these complexes have the same structure independent of the temperature of the solid or in aqueous solution. $^{35,36}$

The number of tetra- and pentaaquacopper(II) complexes with no other ligands within the sum of the van der Waals radii $^{37}$ reported in crystallographic studies is low. Only four structures, each with a tetra- or pentaaquacopper(II) ion, have been reported (Table S3). Due to the limited number of such reported structures, the literature search was extended to all four-and five-coordinate copper(II) complexes with oxygen donor ligands. The four-coordinate complexes have all a square-planar coordination geometry with a mean $\mathrm{Cu}-\mathrm{O}$ bond distance of $1.928 \AA$ (68 structures) (Table S3). Of the fivecoordinate copper(II) complexes with oxygen donor ligands all except one display a tetragonally elongated square-pyramidal geometry, with the last one being a trigonal bipyramid (Table S3). The mean $\mathrm{Cu}-\mathrm{O}$ bond distance in the square-pyramidal copper(II) complexes is $1.955 \AA$ in the equatorial plane and $2.258 \AA$ to the ligand in the axial position (37 structures) (Table S3). 
To summarize the present knowledge about the structure of the hydrated copper(II) ion in aqueous solution, (1) there is strong evidence that it is noncentrosymmetric, as shown by linear electric field $\mathrm{EPR}^{6,7}$ and X-ray absorption spectroscopy studies, ${ }^{13,22,25}$ (2) different kinds of theoretical simulations have shown that $\left[\mathrm{Cu}\left(\mathrm{H}_{2} \mathrm{O}\right)_{5}\right]^{2+}$ and $\left[\mathrm{Cu}\left(\mathrm{H}_{2} \mathrm{O}\right)_{5} \cdot \cdot \mathrm{H}_{2} \mathrm{O}\right]^{2+}$ units are more stable in aqueous solution in comparison to a regular Jahn-Teller distorted $\left[\mathrm{Cu}\left(\mathrm{H}_{2} \mathrm{O}\right)_{6}\right]^{2+}$ ion, ${ }^{9-16,21-23,25}$ and (3) solid-state structures containing $\left[\mathrm{Cu}\left(\mathrm{H}_{2} \mathrm{O}\right)_{6}\right]^{2+}$ ions crystallize in noncentrosymmetric space groups or in centrosymmetric space groups but the copper in $\left[\mathrm{Cu}\left(\mathrm{H}_{2} \mathrm{O}\right)_{6}\right]^{2+}$ is not in the center of symmetry and $\left[\mathrm{Cu}\left(\mathrm{H}_{2} \mathrm{O}\right)_{5}\left(\mathrm{O}^{\prime}\right)\right]$ complexes display a significant difference in the axial $\mathrm{Cu}-\mathrm{O}$ bond distances as discussed above.

The aim of this study is to collect high-quality EXAFS data to high $k$ values of solvated copper(II) ions in solution in series of oxygen donor solvents and to test which of the three different models, a tetragonally elongated square pyramid (5coordination) and tetragonally elongated octahedra with the same or different axial $\mathrm{Cu}-\mathrm{O}$ bond distances (6-coordination), fit the data best and to make comparisons to previously reported EXAFS and MXAN studies ${ }^{13,22,25}$ on the hydrated copper(II) ion in aqueous solution. The studied solvents all have similar physicochemical properties (Table S4) and represent increasing spatial demand upon coordination in order to study whether lower coordination numbers are present for the solvents most space-demanding at coordination. For example, it has previously been reported that the copper(II) ion is four-coordinate in hexamethylphosphoric triamide, a space-demanding solvent at coordination. ${ }^{38}$ Another aim is to confirm or disprove whether the $\mathrm{Cu}-\mathrm{O}$ bond distances reported in the crystal structures of $[\mathrm{Cu}$ $\left.\left(\mathrm{H}_{2} \mathrm{O}\right)_{6}\right]\left(\mathrm{ClO}_{4}\right)_{2},\left[\mathrm{Cu}\left(\mathrm{H}_{2} \mathrm{O}\right)_{6}\right]\left(\mathrm{BrO}_{3}\right)_{2},\left[\mathrm{Cu}\left(\mathrm{H}_{2} \mathrm{O}\right)_{6}\right] \mathrm{SiF}_{6}, \mathrm{Cu}-$ $\left(\mathrm{NO}_{3}\right)_{2} \cdot 2.5 \mathrm{H}_{2} \mathrm{O}$, and $\mathrm{CuSO}_{4} \cdot 5 \mathrm{H}_{2} \mathrm{O}$ are in agreement with the $\mathrm{Cu}-\mathrm{O}$ bond distances obtained by EXAFS. If the crystallographic investigations of the reported structures cannot be confirmed by EXAFS, it becomes evident that crystallographic studies of compounds crystallizing in e.g. centrosymmetric space groups may result in structural information with higher symmetry in comparison to the individual units, e.g. metal complexes, thereby leading to an incorrect description.

\section{EXPERIMENTAL SECTION}

Chemicals. Methanol $\left(\mathrm{CH}_{3} \mathrm{OH} ; \mathrm{MeOH}\right), \mathrm{N}, \mathrm{N}$-dimethylformamide $\left(\left(\mathrm{CH}_{3}\right)_{2} \mathrm{NCHO} ; \mathrm{dmf}\right), \quad \mathrm{N}, \mathrm{N}$-diethylformamide $\left(\left(\mathrm{CH}_{3} \mathrm{CH}_{2}\right)_{2} \mathrm{NCHO} ;\right.$ def $), \mathrm{N}, \mathrm{N}$-dimethylacetamide $\left(\left(\mathrm{CH}_{3}\right)_{2} \mathrm{NC}\right.$ $\left.\left(\mathrm{CH}_{3}\right) \mathrm{O} ; \mathrm{dma}\right), \mathrm{N}, \mathrm{N}$-diethylacetamide $\left(\left(\mathrm{CH}_{3} \mathrm{CH}_{2}\right)_{2} \mathrm{NC}\left(\mathrm{CH}_{3}\right) \mathrm{O}\right.$; dea), $\mathrm{N}, \mathrm{N}$-dimethylpropionamide $\left(\left(\mathrm{CH}_{3}\right)_{2} \mathrm{NC}\left(\mathrm{CH}_{3} \mathrm{CH}_{2}\right) \mathrm{O} ; \mathrm{dmp}\right)$, $\mathrm{N}$,N-diethylpropionamide $\left(\left(\mathrm{CH}_{3} \mathrm{CH}_{2}\right)_{2} \mathrm{NC}\left(\mathrm{CH}_{3} \mathrm{CH}_{2}\right) \mathrm{O}\right.$; dep $)$, $N, N, N^{\prime}, \mathrm{N}^{\prime}$-tetramethylurea $\left(\left(\mathrm{CH}_{3}\right)_{2} \mathrm{~N}\right)_{2} \mathrm{CO}$; tmu $)$, and $N, N^{\prime}$-dimethylpropyleneurea $\left(\left(\mathrm{CH}_{2}\right)_{3} \mathrm{~N}\left(\mathrm{CH}_{3}\right)_{2} \mathrm{CO}\right.$; dmpu), all Sigma-Aldrich, were used as purchased except for dmpu, which was purified by distillation over calcium hydride $\left(\mathrm{CaH}_{2} ;\right.$ Merck $)$ under reduced pressure and stored over $3 \AA$ molecular sieves in a dark bottle. Deionized water that was further purified by a Milli-Q Plus Ultrapure water system, giving water with $18.2 \mathrm{M} \Omega \mathrm{cm}$ resistance was used in syntheses of the hydrated copper(II) salts and in the preparation of aqueous solutions.

Copper powder (Aldrich, 99.9999\% purity, lot \#1297) was dissolved in concentrated nitric acid (Merck, analytical grade). After a part of the obtained solution was cooled in a refrigerator, solid copper(II) nitrate hemipentahydrate $\left(\mathrm{Cu}\left(\mathrm{NO}_{3}\right)_{2} \cdot 2.5 \mathrm{H}_{2} \mathrm{O}\right)$ precipitated. After dilution of the remaining part of this solution with deionized water, a $5 \mathrm{~mol} \mathrm{dm}{ }^{-3}$ sodium hydroxide solution (prepared from sodium hydroxide $(\mathrm{NaOH}$; Merck, analytical grade) was added to precipitate copper(II) hydroxide, which was rinsed several times with water. Anhydrous copper(II) trifluoromethanesulfonate $(\mathrm{Cu}$ $\left.\left(\mathrm{CF}_{3} \mathrm{SO}_{3}\right)_{2}\right)$ was prepared by adding an excess of trifluoromethanesulfonic acid $\left(\mathrm{CF}_{3} \mathrm{SO}_{3} \mathrm{H}\right.$; Fluka) dropwise to an aqueous slurry of copper(II) hydroxide until a clear solution was obtained. The obtained solution was filtered, and water and excess acid were boiled off at approximately $450 \mathrm{~K}$ in an oven. The resulting anhydrous copper(II) trifluoromethanesulfonate was repeatedly ground using a mortar and pestle with oven drying at $450 \mathrm{~K}$ in between until a fine, dry, almost white powder was obtained. The dry salt was stored in the oven at $450 \mathrm{~K}$ to avoid uptake of water. Hexaaquacopper(II) perchlorate $\left(\left[\mathrm{Cu}\left(\mathrm{H}_{2} \mathrm{O}\right)_{6}\right]\left(\mathrm{ClO}_{4}\right)_{2}\right)$ was prepared by dissolving copper(II) hydroxide in dilute perchloric acid $\left(\mathrm{HClO}_{4}\right)$, the volume was reduced, and precipitation took place after cooling in a refrigerator. Copper(II) sulfate pentahydrate $\left(\mathrm{CuSO}_{4} \cdot 5 \mathrm{H}_{2} \mathrm{O}\right)$ was prepared in the same way as the perchlorate salt but using dilute sulfuric acid, prepared from concentrated sulfuric acid (Merck, analytical grade, $98 \%$ ). The identities of the prepared solid compounds were confirmed by determinations of the unit cell parameters crystallographically.

Solutions and Crystals. The solutions for the EXAFS studies were prepared by dissolving anhydrous copper(II) trifluoromethanesulfonate in the respective solvent to a concentration of $0.19 \mathrm{~mol}$ $\mathrm{dm}^{-3}$ (Table S5). All solutions, except the dmpu and tmu solutions, are light blue with somewhat different hues. The dmpu and tmu solutions are dark green. In another experiment a saturated copper(II) trifluoromethanesulfonate dmpu solution was stored in a refrigerator for several years. Only low-quality single-crystals of tetrakis $\left(N, N^{\prime}\right.$ dimethylpropyleneurea)copper(II) trifluoromethanesulfonate monosolvate $\left(\left[\mathrm{Cu}(\mathrm{dmpu})_{4}\right]\left(\mathrm{CF}_{3} \mathrm{SO}_{3}\right)_{2} \cdot \mathrm{dmpu} ; 1\right)$ were obtained. The reported crystal structure represents the best of these. Repeated attempts to prepare better crystals, using different common methods, failed.

Balder Beamline at the MAX IV Synchrotron Light Facility, Lund, Sweden. Copper K-edge X-ray absorption data were collected in transmission mode at the Balder beamline at the MAX IV synchrotron light facility, Lund University, Lund, Sweden. Balder is a new high-flux wiggler beamline for X-ray absorption and emission spectroscopy at the $3.0 \mathrm{GeV}$ storage ring. ${ }^{39}$ High data acquisition speed is crucial to be able to perform X-ray spectroscopy experiments over $2000 \mathrm{eV}$ without significant radiation damage. The doublecrystal fixed exit monochromator (DCM) (FMB Oxford) is equipped with a direct drive motor on the Bragg axis, allowing for scan speeds up to $0.5 \mathrm{~s} / 1000 \mathrm{eV}$. In the current configuration of the data acquisition a full EXAFS scan can be performed within acquisition times down to $12 \mathrm{~s}$. Spectra were acquired using a continuous scan scheme, where the Bragg axis as well as the vertical beam offset are moved simultaneously with constant velocity to fix the vertical position of the beam. The Bragg axis is equipped with a rotary encoder with a resulting resolution of 50 counts $/ \mu \mathrm{rad}$. Data acquisition was performed using an Em\# electrometer device, ${ }^{40}$ which is an MAX IV codevelopment together with ALBA of Spain. The acquisition is (hardware) triggered at predefined positions of the Bragg axis on the basis of a comparison of the encoder readout with a look-up table of trigger positions at FPGA (field programmable gate array) level utilizing the PandABox developed at Soleil in France, and Diamond in the United Kingdom. ${ }^{41}$ The DCM is equipped with two sets of crystals, $\mathrm{Si}(111)$ and $\mathrm{Si}(311)$, of which the $\mathrm{Si}(111)$ crystal set was employed in this study. A vertically position sensitive ionization chamber is coupled in closed-loop operation to a piezo drive on the pitch axis of the second monochromator crystal for further stabilization of the beam position on the sample during a scan. Custom-developed ionization chambers were used for transmission measurements. The ion chambers are $30 \mathrm{~cm}$ long; the first one, $\mathrm{I}_{0}$, contained 1.5 bar of $\mathrm{N}_{2}$ (applied potential $2.0 \mathrm{kV}$ ) and the second one, $\mathrm{I}_{1}$, contained 0.2 bar of $\mathrm{Ar}$ and 1.8 bar of $\mathrm{N}_{2}$ (applied potential $2.5 \mathrm{kV})$.

Extended X-ray Absorption Fine Structure (EXAFS). The copper K-edge X-ray absorption data in this study were collected in transmission mode. The liquid sample cells were made of a $3.0 \mathrm{~mm}$ 
Teflon spacer and Kapton foil windows held together with titanium frames. The solid samples were measured as pressed pellets with cellulose or polyethylene as the binding medium. The XAS spectra were measured in continuous energy scanning at a speed of $50 \mathrm{~s} /$ full EXAFS spectrum $\left(k_{\max }=18 \AA^{-1}\right)$. The monochromatic flux at the sample was $\sim 10^{12}$ photons/s with a spot size of approximately 0.10 (horizontal) $\times 2.0$ (vertical) $\mathrm{mm}$. For each sample, 20 repeats were examined for possible radiation damage and afterward accumulated into an average spectrum. Radiation damage, if it happens, is in solid samples seen as sharp bends on the absorption coefficient curves and as color variation of the sample visible live by a macro camera. In general, only a single EXAFS scan was recorded on each sample position. Immediately before the start of each repeat, the sample was shifted by $0.20 \mathrm{~mm}$ horizontally into a fresh position to avoid radiation dose accumulation. It was seen that aqueous solutions and solid hydrates were the most prone to radiation damage, due to water radiolysis as reported before. ${ }^{42}$ In such cases, when bubbles were seen rapidly forming or abnormal changes in the EXAFS spectrum were observed, the scanning speed was increased to $25 \mathrm{~s} /$ full EXAFS spectrum. The energy axis was calibrated with repeated spectra of a copper foil with the first inflection point assigned as $8980.3 \mathrm{eV} .{ }^{43}$ The EXAFSPAK $^{44}$ program package was used for data treatment. The EXAFS oscillations were extracted using standard procedures for preedge subtraction, spline removal, and data normalization. ${ }^{45}$ Model fitting, including both single and multiple backscattering pathways, was performed with theoretical phase and amplitude functions calculated $a b$ initio by means of the computer code FEFF7. ${ }^{46}$ The $k^{3}$-weighted EXAFS oscillation was analyzed using a nonlinear leastsquares fitting procedure.

Large-Angle X-ray Scattering (LAXS). The scattering from the free surface of a saturated dmpu solution of copper(II) trifluoromethanesulfonate, $\left(\sim 0.8 \mathrm{~mol} \mathrm{dm}^{-3}\right)$ was measured with a large-angle $\theta-\theta$ goniometer, as previously described. ${ }^{47,48}$ Intensity data were collected in the range $1<\theta<65^{\circ}$ using Mo K $\alpha$ radiation $(\lambda=0.7107$ $\AA$ ), following the same procedure as described elsewhere. ${ }^{49}$ The experimental intensities were corrected for absorption and polarization and normalized to a stoichiometric unit of volume corresponding to one copper atom. After subtraction of the structure-independent coherent and Compton scattering, the remaining structure-dependent intensity function $i(s)$ was Fouriertransformed to obtain a modified radial distribution function (RDF), expressed in the form $D(r)-4 \pi r^{2} r_{0}$. Minor erroneous peaks below $1.2 \AA$ in the RDFs were removed by a Fourier back-transform procedure to align the intensity function before fitting the model functions. The KURVLR program ${ }^{50}$ was used for data treatment and the STEPLR program ${ }^{51}$ for least-squares refinements of model parameters by comparing calculated intensity contributions for distinct interatomic interactions with the experimental reduced intensities for values of $s>3.7 \AA^{-1}(s=(4 \pi / \lambda) \sin \theta)$.

Single-Crystal X-ray Diffraction. Data collection were performed on a Bruker SMART platform equipped with a CCD area detector and a graphite monochromator using Mo $\mathrm{K} \alpha(\lambda=0.7107 \AA)$ radiation at ambient room temperature. A hemisphere of data with 1271 frames was collected using the $\omega$ scan method $\left(0.3^{\circ}\right.$ frame width). The crystal to detector distance was $50 \mathrm{~mm}$. The first 50 frames were remeasured at the end of the data collection to monitor crystal and instrument stability. The structure was solved by direct methods in the SHELX 2016/6 program package ${ }^{52}$ and refined using full-matrix least squares on $F^{2}$.

Non-hydrogen atoms were treated anisotropically. Hydrogen atoms were calculated in ideal positions riding on their respective carbon atoms. Crystal and experimental data for $\mathbf{1}$ are summarized in Table 1.

UV-Vis Spectrophotometry. A PerkinElmer Lambda 2 doublebeam spectrophotometer was used to record the UV-vis spectra of the copper(II) trifluoromethanesulfonate solutions studied by EXAFS. The recorded spectra after appropriate dilution are shown in Figure S1.
Table 1. Crystallographic Data for 1

\begin{tabular}{|c|c|}
\hline & $\mathrm{C}_{38} \mathrm{H}_{72} \mathrm{CuF}_{6} \mathrm{~N}_{12} \mathrm{O}_{12} \mathrm{~S}_{2}$ \\
\hline $\mathrm{mol} \mathrm{wt}$ & 1130.73 \\
\hline cryst syst & monoclinic \\
\hline space group & $P 2_{1} / c$ \\
\hline$a / \AA ̊$ & $12.629(6)$ \\
\hline$b / \AA$ & $21.740(10)$ \\
\hline$c / \AA$ & $10.050(5)$ \\
\hline$\alpha / \operatorname{deg}$ & 90 \\
\hline$\beta / \operatorname{deg}$ & $103.046(8)$ \\
\hline$\gamma / \mathrm{deg}$ & 90 \\
\hline$V / \AA^{3}$ & $2688(2)$ \\
\hline$T / K$ & $298(2)$ \\
\hline$Z$ & 2 \\
\hline$\rho_{\text {calcd }} / \mathrm{g} \mathrm{cm}^{-3}$ & 1.397 \\
\hline$\mu / \mathrm{mm}^{-1}$ & 0.570 \\
\hline cryst size $/ \mathrm{mm}$ & $0.27 \times 0.22 \times 0.18$ \\
\hline$\theta$ range/deg & $1.66-25.68$ \\
\hline index ranges & $-15 \leq h \leq 15,-23 \leq k \leq 26,-11 \leq l \leq 12$ \\
\hline no. of measd rflns & 13755 \\
\hline no. of unique rflns $\left(R_{\text {int }}\right)$ & $5094(0.0511)$ \\
\hline refinement method & full-matrix least squares on $F^{2}$ \\
\hline final R1, wR2 $(I>2 \sigma(I))^{a}$ & $0.0727,0.1960$ \\
\hline final R1, wR2 (all data) ${ }^{a}$ & $0.1197,0.2324$ \\
\hline max diff peak/e $\AA^{-3}$ & 0.377 \\
\hline max diff hole/e $\AA^{-3}$ & -0.273 \\
\hline $\begin{array}{l}{ }^{a} R \text { values are defined a } \\
{\left[\sum\left[w\left(F_{\mathrm{o}}^{2}-F_{\mathrm{c}}{ }^{2}\right)\right] / \sum[w(\right.}\end{array}$ & $\begin{array}{l}\mathrm{R} 1=\sum \| F_{\mathrm{o}}|-| F_{\mathrm{c}}|| / \sum\left|F_{\mathrm{o}}\right| \text { and } \mathrm{wR} 2 \\
\left.\left.\mathrm{o})^{2}\right]\right]^{0.5} .\end{array}$ \\
\hline
\end{tabular}

\section{RESULTS AND DISCUSSION}

EXAFS Study of the Hydrated Copper(II) ion in Aqueous Solution and the Solid State. In this study EXAFS data on an aqueous solution of copper(II) trifluoromethanesulfonate and the solids $\left[\mathrm{Cu}\left(\mathrm{H}_{2} \mathrm{O}\right)_{6}\right]\left(\mathrm{ClO}_{4}\right)_{2}, \mathrm{Cu}-$ $\left(\mathrm{NO}_{3}\right)_{2} \cdot 2.5 \mathrm{H}_{2} \mathrm{O}$, and $\mathrm{CuSO}_{4} \cdot 5 \mathrm{H}_{2} \mathrm{O}$ have been collected at the Balder beamline. They are compared with data on a $0.50 \mathrm{~mol}$ $\mathrm{dm}^{-3}$ aqueous solution of copper(II) perchlorate and the solids $\left[\mathrm{Cu}\left(\mathrm{H}_{2} \mathrm{O}\right)_{6}\right]\left(\mathrm{BrO}_{3}\right)_{2}$, and $\left[\mathrm{Cu}\left(\mathrm{H}_{2} \mathrm{O}\right)_{6}\right] \mathrm{SiF}_{6}$, collected at beamline 4-1 (old station) at the Stanford Synchrotron Radiation Lightsource (SSRL), reported in ref 34. The EXAFS spectra of the aqueous solutions and the solids $\left[\mathrm{Cu}\left(\mathrm{H}_{2} \mathrm{O}\right)_{6}\right]\left(\mathrm{ClO}_{4}\right)_{2}$, $\left[\mathrm{Cu}\left(\mathrm{H}_{2} \mathrm{O}\right)_{6}\right]\left(\mathrm{BrO}_{3}\right)_{2}$, and $\left[\mathrm{Cu}\left(\mathrm{H}_{2} \mathrm{O}\right)_{6}\right] \mathrm{SiF}_{6}$ almost superimpose each other, showing that they have identical or at least very similar structures (Figure 1). Also solid $\mathrm{Cu}\left(\mathrm{NO}_{3}\right)_{2}$. $2.5 \mathrm{H}_{2} \mathrm{O}$ almost superimposes with the aqueous copper(II) solutions, implying a structural similarity even though copper(II) binds nitrate oxygens in the equatorial and axial positions $^{53-55}$ (Figure 1). The data collected at SSRL have been refitted with the three models used in this study. The results of the refinements of the EXAFS data of the aqueous solutions and these solids are summarized in Table 2. The best fit of the hydrated copper(II) ion in aqueous solution is obtained by a model with four $\mathrm{Cu}-\mathrm{O}_{\mathrm{eq}}$ bond distances in the equatorial plane at 1.956(3) $\AA$ and two separate $\mathrm{Cu}-\mathrm{O}_{\mathrm{ax}}$ bond distances of 2.14(2) and 2.32(2) $\AA$, which are in close agreement with an EXAFS study reported by Frank et al. ${ }^{22}$ In the solids $\left[\mathrm{Cu}\left(\mathrm{H}_{2} \mathrm{O}\right)_{6}\right]\left(\mathrm{ClO}_{4}\right)_{2}$ and $\left[\mathrm{Cu}\left(\mathrm{H}_{2} \mathrm{O}\right)_{6}\right] \mathrm{SiF}_{6}$, the $\mathrm{Cu}-$ $\mathrm{O}_{\mathrm{eq}}$ bond distances are within the limit of errors the same, $1.963(6) \AA$, the $\mathrm{Cu}-\mathrm{O}_{\mathrm{ax}}$ bond distances are slightly longer than those in aqueous solution, 2.18(1), 2.34(1) $\AA$ and 2.21(2), 2.32(3) $\AA$, respectively. In solid $\left[\mathrm{Cu}\left(\mathrm{H}_{2} \mathrm{O}\right)_{6}\right]\left(\mathrm{BrO}_{3}\right)_{2}$ 


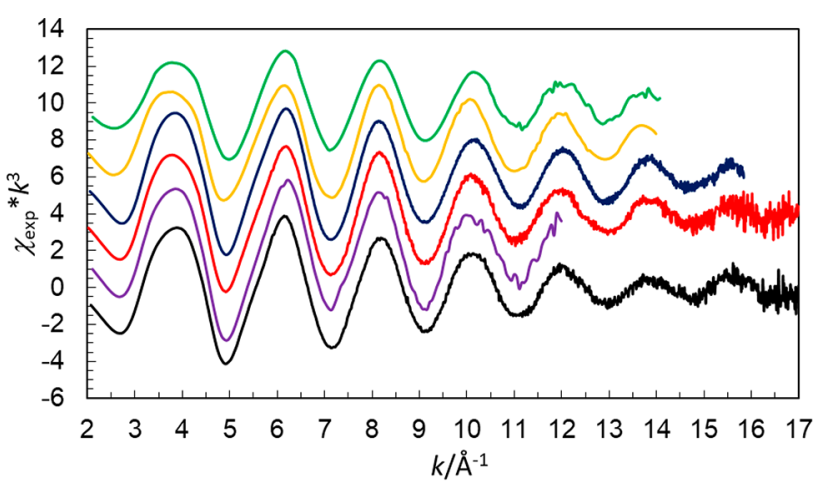

Figure 1. Raw EXAFS spectra of a $0.20 \mathrm{~mol} \mathrm{dm}^{-3}$ aqueous copper(II) trifluoromethanesulfonate solution (black line), $0.50 \mathrm{~mol} \mathrm{dm}^{-3}$ aqueous copper(II) perchlorate solution (reported in ref 34, purple line, offset 4), solid $\left[\mathrm{Cu}\left(\mathrm{H}_{2} \mathrm{O}\right)_{6}\right]\left(\mathrm{ClO}_{4}\right)_{2}$ (red line, offset 4), solid $\mathrm{Cu}\left(\mathrm{NO}_{3}\right)_{2} \cdot 2.5 \mathrm{H}_{2} \mathrm{O}$ (blue line, offset 6), solid $\left[\mathrm{Cu}\left(\mathrm{H}_{2} \mathrm{O}\right)_{6}\right]\left(\mathrm{BrO}_{4}\right)_{2}$ (reported in ref 34 , yellow line, offset 8 ), and $\left[\mathrm{Cu}\left(\mathrm{H}_{2} \mathrm{O}\right)_{6}\right] \mathrm{SiF}_{6}$ (reported in ref 34, green line, offset 10).

the $\mathrm{Cu}-\mathrm{O}_{\mathrm{eq}}$ and $\mathrm{Cu}-\mathrm{O}_{\mathrm{ax}}$ bond distances are slightly longer, 1.967(5), 2.21(2) $\AA$ and 2.42(2) $\AA$.

The mean $\mathrm{Cu}-\mathrm{O}_{\mathrm{eq}}$ and $\mathrm{Cu}-\mathrm{O}_{\mathrm{ax}}$ bond distance in solid $\mathrm{Cu}\left(\mathrm{NO}_{3}\right)_{2} \cdot 2.5 \mathrm{H}_{2} \mathrm{O}$ have been refined to $1.959(3), 2.176(6)$, and 2.39(1) Å, respectively (Table 2). The fitting using models with copper binding four solvent molecules in the equatorial plane and two in an axial position at the same $\mathrm{Cu}-\mathrm{O}_{\mathrm{ax}}$ bond distance (centrosymmetric Jahn-Teller distorted-octahedral geometry) or only one solvent molecule in the axial position of a tetragonally elongated square pyramid are slightly worse than the model with different bond distances in the axial positions.
The structure parameters obtained in the refinements applying these models are given in Table 2 and Table S6. The fit of raw EXAFS data and the Fourier transforms are shown in Figures 2 and 3 , respectively.

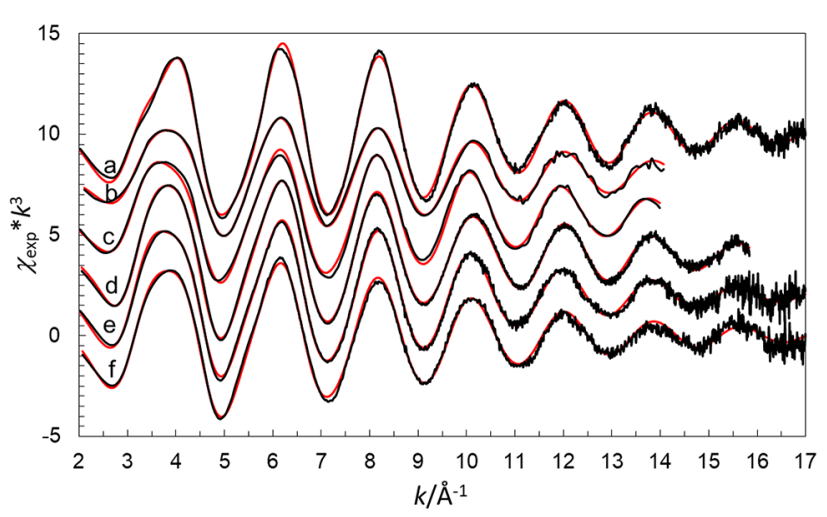

Figure 2. Fit of raw EXAFS data of (a) solid copper(II) sulfate pentahydrate $\left(\mathrm{CuSO}_{4} \cdot 5 \mathrm{H}_{2} \mathrm{O}\right.$, offset 10$)$, (b) solid hexaaquacopper(II) hexafluorosilicate $\left(\left[\mathrm{Cu}\left(\mathrm{H}_{2} \mathrm{O}\right)_{6}\right] \mathrm{SiF}_{6}\right.$, offset 8$)$, (c) solid hexaaquacopper(II) bromate $\left(\left[\mathrm{Cu}\left(\mathrm{H}_{2} \mathrm{O}\right)_{6}\right]\left(\mathrm{BrO}_{3}\right)_{2}\right.$, offset 6), (d) solid hexaaquacopper(II) nitrate $\left(\mathrm{Cu}\left(\mathrm{NO}_{3}\right)_{2} \cdot 2.5 \mathrm{H}_{2} \mathrm{O}\right.$, offset 4$)$, (e) solid hexaaquacopper(II) perchlorate $\left(\left[\mathrm{Cu}\left(\mathrm{H}_{2} \mathrm{O}\right)_{6}\right]\left(\mathrm{ClO}_{4}\right)_{2}\right.$, offset 2$)$, and (f) aqueous solution of copper(II) trifluoromethanesulfonate (no offset).

The three crystallographic studies on $\left[\mathrm{Cu}\left(\mathrm{H}_{2} \mathrm{O}\right)_{6}\right]\left(\mathrm{ClO}_{4}\right)_{2}$ have reported very different $\mathrm{Cu}-\mathrm{O}$ bond distance distributions, in spite of reporting the same space group, $P 2_{1} / \mathrm{c}$ (No. 14) (Table S7). ${ }^{56-58}$ Two of these report very similar unit cell

Table 2. Summary of Refinements of EXAFS Data Using a Noncentrosymmetric Tetragonally Elongated Octahedral Geometry of the Hydrated Copper(II) ion in Water (aq) and the Solid State for $\left[\mathrm{Cu}\left(\mathrm{H}_{2} \mathrm{O}\right)_{6}\right]\left(\mathrm{ClO}_{4}\right)_{2}(\mathrm{~A}), \mathrm{Cu}\left(\mathrm{NO}_{3}\right)_{2} \cdot 2.5 \mathrm{H}_{2} \mathrm{O}(\mathrm{B}), \mathrm{CuSO}$. $5 \mathrm{H}_{2} \mathrm{O}(\mathrm{C}),\left[\mathrm{Cu}\left(\mathrm{H}_{2} \mathrm{O}\right)_{6}\right]\left(\mathrm{BrO}_{3}\right)_{2}(\mathrm{D})$, and $\left[\mathrm{Cu}\left(\mathrm{H}_{2} \mathrm{O}\right)_{6}\right] \mathrm{SiF}_{6}(\mathrm{E})^{a}$

\begin{tabular}{|c|c|c|c|c|c|c|c|}
\hline & water & water* & A & B & C & $D^{*}$ & $\mathrm{E}^{*}$ \\
\hline$d\left(\mathrm{Cu}-\mathrm{O}_{\mathrm{eq}}\right)$ & $1.957(3)$ & $1.954(8)$ & $1.963(3)$ & $1.959(3)$ & $1.959(3)$ & $1.967(5)$ & $1.962(6)$ \\
\hline$\sigma^{2}\left(\mathrm{Cu}-\mathrm{O}_{\mathrm{eq}}\right)$ & $0.0055(3)$ & $0.0069(8)$ & $0.0060(3)$ & $0.0052(3)$ & $0.0051(3)$ & $0.0052(7)$ & $0.0050(8)$ \\
\hline$n\left(\mathrm{Cu}-\mathrm{O}_{\mathrm{eq}}\right)$ & 4 & 4 & 4 & 4 & 4 & 4 & 4 \\
\hline$d\left(\mathrm{Cu}-\mathrm{O}_{\mathrm{axl}}\right)$ & $2.14(2)$ & $2.15(5)$ & $2.184(8)$ & $2.176(6)$ & $2.218(9)$ & $2.21(2)$ & $2.21(2)$ \\
\hline$\sigma^{2}\left(\mathrm{Cu}-\mathrm{O}_{\mathrm{axl}}\right)$ & $0.007(2)$ & $0.012(6)$ & $0.0065(9)$ & $0.0072(6)$ & $0.0066(7)$ & $0.010(2)$ & $0.011(4)$ \\
\hline$n\left(\mathrm{Cu}-\mathrm{O}_{\mathrm{axl}}\right)$ & 1 & 1 & 1 & 1 & 1 & 1 & 1 \\
\hline$d\left(\mathrm{Cu}-\mathrm{O}_{\mathrm{ax2}}\right)$ & $2.32(2)$ & $2.36(4)$ & $2.343(8)$ & $2.394(8)$ & $2.376(9)$ & $2.42(2)$ & $2.32(3)$ \\
\hline$\sigma^{2}\left(\mathrm{Cu}-\mathrm{O}_{\mathrm{ax2}}\right)$ & $0.009(2)$ & $0.014(6)$ & $0.0076(8)$ & $0.0084(8)$ & $0.0074(9)$ & $0.010(2)$ & $0.012(3)$ \\
\hline$n\left(\mathrm{Cu}-\mathrm{O}_{\mathrm{ax2}}\right)$ & 1 & 1 & 1 & 1 & 1 & 1 & 1 \\
\hline$d\left(\mathrm{MS}\left(\mathrm{CuO}_{4}\right)\right)$ & $3.914^{b}$ & $3.908^{b}$ & $3.926^{b}$ & $3.917^{b}$ & $3.918^{b}$ & $3.934^{b}$ & $3.924^{b}$ \\
\hline$\sigma^{2}\left(\mathrm{MS}\left(\mathrm{CuO}_{4}\right)\right)$ & $0.012(3)$ & $0.013(4)$ & $0.010(3)$ & $0.010(2)$ & $0.032(3)$ & $0.010(4)$ & $0.010(4)$ \\
\hline$n\left(\mathrm{MS}\left(\mathrm{CuO}_{4}\right)\right)$ & $3 * 4$ & $3 * 4$ & $3 * 4$ & $3 * 4$ & $3 * 4$ & $3 * 4$ & $3 * 4$ \\
\hline$d\left(\mathrm{Cu}-\mathrm{S}_{1}\right)$ & & & & & $3.58(2)$ & & \\
\hline$\sigma^{2}\left(\mathrm{Cu}-\mathrm{S}_{1}\right)$ & & & & & $0.012(3)$ & & \\
\hline$n\left(\mathrm{Cu}-\mathrm{S}_{1}\right)$ & & & & & 1 & & \\
\hline$d\left(\mathrm{Cu}-\mathrm{S}_{2}\right)$ & & & & & $3.74(7)$ & & \\
\hline$\sigma^{2}\left(\mathrm{Cu}-\mathrm{S}_{2}\right)$ & & & & & $0.024(8)$ & & \\
\hline$n\left(\mathrm{Cu}-\mathrm{S}_{2}\right)$ & & & & & 1 & & \\
\hline$S_{0}{ }^{2}$ & $0.93(4)$ & $1.03(4)$ & $1.06(4)$ & $0.95(3)$ & $1.05(3)$ & $0.72(5)$ & $0.84(5)$ \\
\hline$E_{0}$ & $8989.7(5)$ & $8988.7(6)$ & $8989.6(5)$ & $8989.6(3)$ & $8989.9(5)$ & $8989.5(5)$ & $8989.9(5)$ \\
\hline$F$ & 18.14 & 8.19 & 16.36 & 7.98 & 12.85 & 8.19 & 9.69 \\
\hline
\end{tabular}

${ }^{a}$ Definitions: distance, $d / \AA$; Debye-Waller coefficient, $\sigma^{2} / \AA^{2}$; number of distances, $n$; amplitude reduction factor, $S_{0}{ }^{2}$; threshold energy, $E_{0} / \mathrm{eV}$; weighted $F$ factor, $F$. The asterisk denotes data collected at SSRL in 2001. Estimated errors within parentheses include the statistical errors from the refinements and estimated experimental errors. Parameters without following parentheses have been fixed. ${ }^{b}$ The linear multiple scattering distance with in the $\mathrm{CuO}_{4}$ equatorial plane has been linked to the $\mathrm{Cu}-\mathrm{O}$ bond distance. 


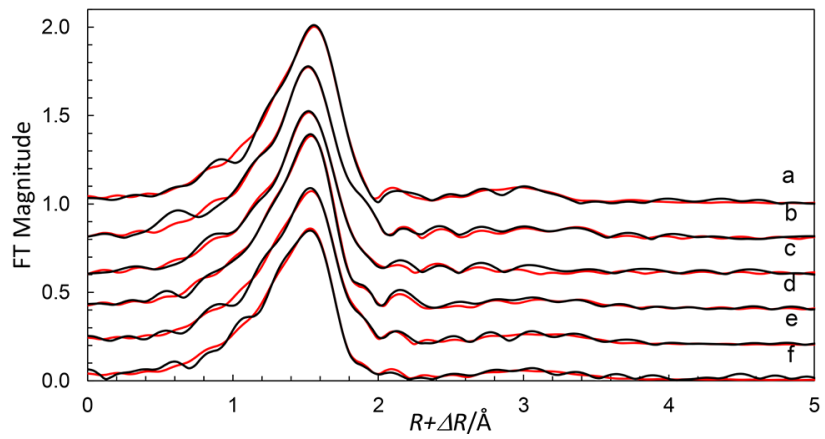

Figure 3. Fit of Fourier transforms of EXAFS data of (a) solid copper(II) sulfate pentahydrate $\left(\mathrm{CuSO}_{4} \cdot 5 \mathrm{H}_{2} \mathrm{O}\right.$, offset 1.0$)$, (b) solid hexaaquacopper(II) hexafluorosilicate $\left(\left[\mathrm{Cu}\left(\mathrm{H}_{2} \mathrm{O}\right)_{6}\right] \mathrm{SiF}_{6}\right.$, offset 0.8$)$, (c) solid hexaaquacopper(II) bromate $\left(\left[\mathrm{Cu}\left(\mathrm{H}_{2} \mathrm{O}\right)_{6}\right]\left(\mathrm{BrO}_{3}\right)_{2}\right.$, offset $0.6)$, (d) solid hexaaquacopper(II) nitrate $\left(\left[\mathrm{Cu}\left(\mathrm{H}_{2} \mathrm{O}\right)_{6}\right]\left(\mathrm{NO}_{3}\right)_{2}\right.$, offset 0.4$)$, (e) hexaaquacopper(II) perchlorate $\left(\mathrm{Cu}\left(\mathrm{NO}_{3}\right)_{2} \cdot 2.5 \mathrm{H}_{2} \mathrm{O}\right.$, offset 0.2 ), and (f) aqueous solution of copper(II) trifluoromethanesulfonate (no offset).

parameters, ${ }^{56,57}$ while the third study differs significantly ${ }^{58}$ (Table S7). In the first reported structure, ${ }^{56}$ the hydrated copper(II) ion is six-coordinate with the expected $\mathrm{Cu}-\mathrm{O}_{\text {eq }}$ bond distances for a Jahn-Teller distorted complex. By a fit the present EXAFS data with the reported $\mathrm{Cu}-\mathrm{O}$ bond distances fixed, the fit is reasonable but the axial distances are clearly wrong with a very large Debye-Waller coefficient, $\sigma^{2}=$ $0.05 \AA^{2}$, and a remaining wave in the residual (Figure S2a); the corresponding Fourier transform (FT) is shown in Figure S3a. The other two reported structures ${ }^{57,58}$ propose pairwise $\mathrm{Cu}-\mathrm{O}$ bond distances at 2.090, 2.164, and $2.280 \AA$ and 1.969, 2.084, and $2.202 \AA$, respectively, which are in strong contradiction to most other reported hexaaquacopper(II) complexes (Table $\mathrm{S} 1)$. The calculated EXAFS spectra based on the reported $\mathrm{Cu}-$ $\mathrm{O}$ bond distances are almost completely out of phase in comparison to the experimental EXAFS data (Figure S2b,c) and the corresponding FTs in Figure $3 \mathrm{a}$.

The crystallographic studies of $\left[\mathrm{Cu}\left(\mathrm{H}_{2} \mathrm{O}\right)_{6}\right]\left(\mathrm{BrO}_{3}\right)_{2}$ and $\left[\mathrm{Cu}\left(\mathrm{H}_{2} \mathrm{O}\right)_{6}\right] \mathrm{SiF}_{6}$ report a regular octahedral structure of the hexaaquacopper(II) ion with $\mathrm{Cu}-\mathrm{O}$ bond distances of 2.079 and $2.074 \AA$, ${ }^{59,60}$ respectively, but they have been proven to have a nonregular octahedral geometry as reported before. ${ }^{34}$ The calculated EXAFS functions on these structures are completely out of phase with the experimental data (Figure S2d,e) and the corresponding FTs in Figure S3b,c, showing that the reported structures from crystallography cannot be correct as discussed above and before. ${ }^{34}$

The crystal structure of $\mathrm{Cu}\left(\mathrm{NO}_{3}\right)_{2} \cdot 2.5 \mathrm{H}_{2} \mathrm{O}$ has been reported in three papers. ${ }^{53-55}$ Copper(II) binds two water molecules and two nitrate oxygens in the equatorial positions at $\mathrm{Cu}-\mathrm{O}$ bond distances of 1.959 and $1.986 \AA$, respectively and additionally three nitrate oxygens at longer distances, one at $2.391 \AA$ and two close to $2.66 \AA^{53}$ (Table S7b). The other two determinations report slightly different $\mathrm{Cu}-\mathrm{O}$ bond distances, 2.476 and two close to $2.62 \AA$ (Table S7b). ${ }^{54,55}$ The fit of the EXAFS data gave a mean $\mathrm{Cu}-\mathrm{O}_{\mathrm{eq}}$ bond distance of $1.959 \AA$ and three longer $\mathrm{Cu}-\mathrm{O}_{\mathrm{ax}} / \mathrm{Cu} \cdots \mathrm{N}$ distances to nitrate ions at 2.183(5), 2.398(5), and 2.734(8) $\AA$. The $\mathrm{Cu}-$ $\mathrm{O}_{\text {eq }}$ bond distance obtained in this EXAFS study is slightly shorter $(1.959(3) \AA)$ than the mean distances in the reported crystallographic investigations (1.972 and $1.990 \AA)^{53,55}$ but is in agreement with the $\mathrm{Cu}-\mathrm{O}_{\mathrm{eq}}$ distances in aqueous solution and the other salts containing hydrated copper(II) ions (Table $2)$. It is interesting to note that the $\mathrm{Cu}-\mathrm{O}$ bond distance at 2.39(1) A fits perfectly, and the longest $\mathrm{Cu}-\mathrm{O} / \mathrm{N}$ distances fit reasonably well with distances reported in the crystallographic study of $\mathrm{Cu}\left(\mathrm{NO}_{3}\right)_{2} \cdot 2.5 \mathrm{H}_{2} \mathrm{O}$. However, these distances cannot be refined without the presence of a relatively short $\mathrm{Cu}-\mathrm{O}_{\mathrm{ax}}$ bond distance, refined to 2.176(6) A, which is absent in the crystal structure. The best possible fit of the EXAFS data with the reported $\mathrm{Cu}-\mathrm{O}$ bond distances in ref 53 is shown in Figure $\mathrm{S} 2 \mathrm{f}$ and the corresponding FT in Figure S3d. In solid $\mathrm{CuSO}_{4}$. $5 \mathrm{H}_{2} \mathrm{O}$, which crystallizes in the centrosymmetric space group $P \overline{1}$ (No. 2), copper binds four water molecules in the equatorial plane and two sulfate oxygens in the axial positions in room-temperature studies. ${ }^{61-66}$ The mean $\mathrm{Cu}-\mathrm{O}_{\text {eq }}$ bond distances in $\mathrm{CuSO}_{4} \cdot 5 \mathrm{H}_{2} \mathrm{O}$ obtained by EXAFS in this study, 1.959(3) A (Table 2), is in very good agreement with those in the reported crystallographic studies. However, for the axial positions two different $\mathrm{Cu}-\mathrm{O}_{\mathrm{ax}}$ bond distances are discerned, 2.22(1) and 2.38(1) $\AA$ (Table 2). The long $\mathrm{Cu}-\mathrm{O}_{\mathrm{ax}, \mathrm{SO} 4}$ bond distance is in good agreement with that reported distances in the crystallographic studies, ${ }^{61-66}$ while the short $\mathrm{Cu}-\mathrm{O}_{\mathrm{ax}, \mathrm{SO} 4}$ bond distance obtained in this EXAFS study is significantly shorter. The fit of the raw EXAFS data and the Fourier transforms of the studied solid copper(II) hydrates are shown in Figures 2 and 3, respectively, and the refined structure parameters are given in Table 2. Also in this case it is proven that the crystallographically determined $\mathrm{Cu}-\mathrm{O}$ bond distances are not in full agreement with the experimental EXAFS data as shown in Figure S2g and the corresponding FT data in Figure S3e.

These results show that the structure of the $\left[\mathrm{Cu}\left(\mathrm{H}_{2} \mathrm{O}\right)_{6}\right]^{2+}$ complex in solid $\left[\mathrm{Cu}\left(\mathrm{H}_{2} \mathrm{O}\right)_{6}\left(\mathrm{ClO}_{4}\right)_{2},\left[\mathrm{Cu}\left(\mathrm{H}_{2} \mathrm{O}\right)_{6}\right]\left(\mathrm{BrO}_{3}\right)_{2}\right.$, and $\left[\mathrm{Cu}\left(\mathrm{H}_{2} \mathrm{O}\right)_{6}\right] \mathrm{SiF}_{6}$, the $\left[\mathrm{Cu}\left(\mathrm{OH}_{2}\right)_{2}\left(\mathrm{ONO}_{2}\right)_{2}\right] \cdot$ unit in $\mathrm{Cu}-$ $\left(\mathrm{NO}_{3}\right)_{2} \cdot 2.5 \mathrm{H}_{2} \mathrm{O}$, and the $\left[\mathrm{Cu}\left(\mathrm{H}_{2} \mathrm{O}\right)_{4}\left(\mathrm{OSO}_{3}\right)_{2}\right]$ unit in $\mathrm{CuSO}_{4}$. $5 \mathrm{H}_{2} \mathrm{O}$ reported from crystallographic studies cannot be confirmed by the lattice-independent EXAFS method. All of the analyzed solid-state structures were solved in centrosymmetric space groups, which required pairwise equal $\mathrm{Cu}-\mathrm{O}$ bond distances or a regular octahedral geometry. It therefore seems likely that the $\mathrm{Cu}-\mathrm{O}_{\mathrm{ax}}$ bonds in these compounds also may have different bond lengths, according to the EXAFS results, and that they are randomly oriented in the solid state in either one dimension, resulting in an apparent centrosymmetric Jahn-Teller distorted-octahedral configuration, or in three dimensions, resulting in regular or slightly distorted octahedra. As a consequence, it seems likely that most of the reported crystal structures containing a hexaaquacopper(II) ion crystallizing in a centrosymmetric space group actually have a similar bond distance distribution in the axial positions, as observed in aqueous solution and the five solids analyzed in this study. It is therefore important to complement crystallographic studies with a lattice-independent method such as EXAFS to secure that a high-symmetry model indeed is the correct one for complexes which may have a lower symmetry. Coordination geometries where such a check is vital are those for metal complexes with Jahn-Teller distorted-octahedral and capped-trigonal-prismatic configurations.

Structure of the Solvated Copper(II) Ion in Methanol and Six Amide Solvents Studied by EXAFS. The structure of the solvated copper(II) ion in methanol, dmf, def, dma, dea, dmp, and dep show the same pattern as in water with four solvent molecules in the equatorial positions at ca. $1.96 \AA$ and two significantly different axial $\mathrm{Cu}-\mathrm{O}$ bond distances. No 


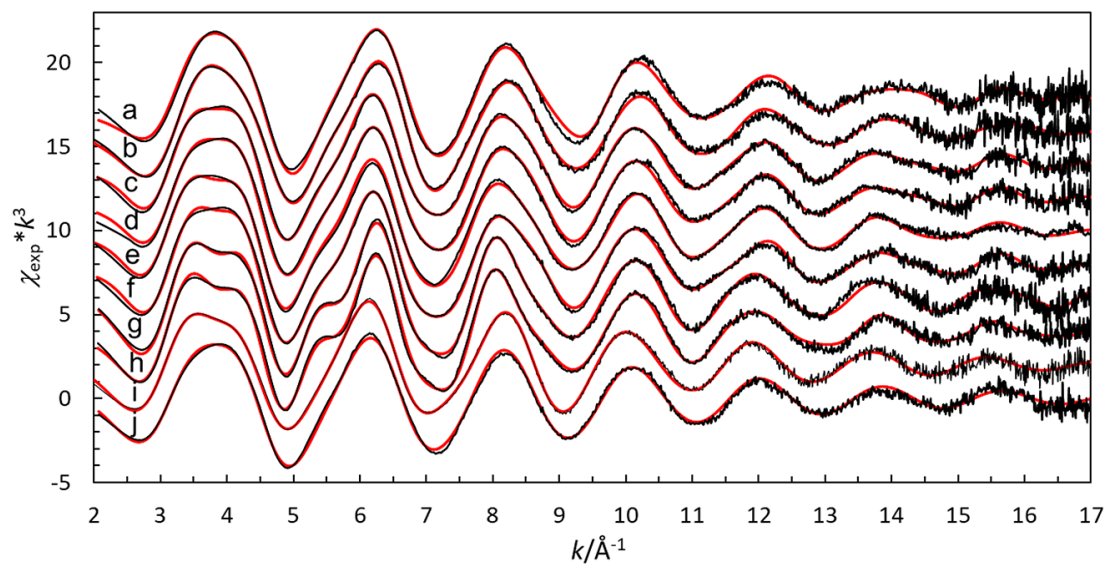

Figure 4. Fit of raw EXAFS data of copper(II) trifluoromethanesulfonate in (a) $N, N$-dimethylpropylene urea (dmpu, offset +18$)$, (b) $N, N, N N^{\prime}$ tetramethylurea (tmu, offset +16 ), (c) N,N-diethylpropionamide (dep, offset +14$)$, (d) N,N-dimethylpropionamide (dmp, offset +12$)$, (e) $N, N$ diethylacetamide (dea, offset +10$)$, (f) $N, N$-dimethylacetamide (dma, offset +8$)$, (g) $N, N$-diethylformamide (def, offset +6$)$, (h) N,Ndimethylformamide $(\mathrm{dmf}$, offset +4$)$, (i) methanol $($ offset +2$)$, and $(j)$ aqueous solution acidified with trifluoromethanesulfonic acid.

homoleptic copper(II) methanol solvate has been reported in the solid state, ${ }^{4}$ and only four copper(II) complexes with four bound methanol molecules have been reported. ${ }^{67-70}$ The mean $\mathrm{Cu}-\mathrm{O}_{\mathrm{eq}}$ bond distance in the methanol-solvated copper(II) ion in solution has been refined to 1.975(4) $\AA$, and the $\mathrm{Cu}-\mathrm{O}_{\mathrm{ax}}$ bond distances have been refined to $2.202(8)$ and 2.34(1) A. The mean $\mathrm{Cu} \cdots \mathrm{C}$ distance and the $\mathrm{Cu}-\mathrm{O}_{\mathrm{eq}}-\mathrm{C}$ three-legged scattering path were refined to $3.03(2)$ and 3.18(4) $\AA$, respectively, which corresponds to a $\mathrm{Cu}-\mathrm{O}-\mathrm{C}$ bond angle of $128(2)^{\circ}$, assuming a $\mathrm{O}-\mathrm{C}$ bond distance of 1.39 $\AA$, which is in full agreement with the bond angles in the reported solid solvates. ${ }^{67-70}$ Zitolo and D'Angelo have reported an EXAFS and MXAN analysis of the methanol solvated copper(II) ion in solution. They tested two models, a tetragonally elongated square-pyramidal and a centrosymmetric Jahn-Teller distorted-octahedral configuration, showing that the tetragonally elongated square pyramid did fit best with a mean $\mathrm{Cu}-\mathrm{O}_{\mathrm{eq}}$ bond distance of $1.98 \AA$, a $\mathrm{Cu}-\mathrm{O}_{\mathrm{ax}}$ distance of $2.27 \AA$, and a mean $\mathrm{Cu}-\mathrm{O}_{\mathrm{eq}}-\mathrm{C}$ bond angle of $129.5^{\circ} .^{26}$ They reported also that the dimethyl sulfoxide and acetonitrile solvated copper(II) ions also have a tetragonally elongated square-pyramidal configuration in solution. ${ }^{26,27}$

Six structures of solid compounds containing a hexakis(dmf)copper(II) ion have been reported, three of which display a Jahn-Teller distorted-octahedral configuration, ${ }^{71-73}$ while the other three have an irregular octahedral geometry. $^{74-76}$ The mean $\mathrm{Cu}-\mathrm{O}_{\text {eq }}$ bond distance in the dmf-solvated copper(II) ion in dmf solution has been refined to 1.963(3) A, and the $\mathrm{Cu}-\mathrm{O}$ bond distances in the axial positions have been refined to $2.178(8)$ and $2.33(1) \AA$. The $\mathrm{Cu} \cdots \mathrm{C}$ distance and the $\mathrm{Cu}-\mathrm{O}-\mathrm{C}$ three-legged scattering path have been refined to $2.855(7)$ and 3.03(2) $\AA$, respectively, which corresponds to a $\mathrm{Cu}-\mathrm{O}-\mathrm{C}$ bond angle of $124(1)^{\circ}$, assuming a $\mathrm{O}=\mathrm{C}$ bond distance of $1.25 \AA$, which is in full agreement with the bond angles in the reported structures containing hexakis $(\mathrm{dmf})$ copper(II) ions. $^{71-76}$

No structures of any hexacoordinate copper(II) complex with the remaining amide solvents used in this study have been reported. $^{4}$ In the structure of tetrakis(dma)copper(II) perchlorate, four dma molecules are bound in the equatorial positions, and perchlorate oxygens are present in the axial positions at long distance but shorter than the van der Waals radii of copper and oxygen. ${ }^{37,77}$ The results of the EXAFS studies of the def-, dma-, dea-, dmp-, and dep-solvated copper(II) ion in the respective solvents are fully in line with the results obtained in dmf. The fit of raw EXAFS data and Fourier transforms are shown in Figures 4 and 5, respectively,

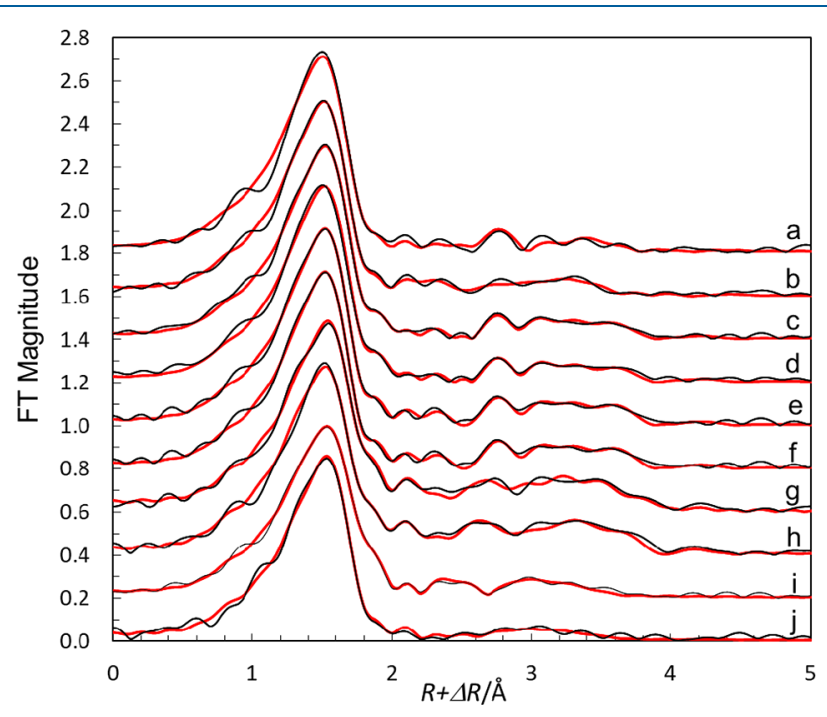

Figure 5. Fit of Fourier transforms of EXAFS data of (a) $N, N$ dimethylpropylene urea (dmpu, offset +1.8$)$, (b) $N, N, N^{\prime}, N^{\prime}$ tetramethylurea (tmu, offset +1.6$)$, (c) $N, N$-diethylpropionamide (dep, offset +1.4$)$, (d) $\mathrm{N}, \mathrm{N}$-dimethylpropionamide (dmp, offset +1.2$)$, (e) $\mathrm{N}, \mathrm{N}$-diethylacetamide (dea, offset +1.0$)$, (f) $\mathrm{N}, \mathrm{N}$-dimethylacetamide (dma, offset +0.8$)$, (g) $\mathrm{N}, \mathrm{N}$-diethylformamide (def, offset +0.6 ), (h) N,N-dimethylformamide (dmf, offset +0.4$)$, (i) methanol (offset $+0.2)$, and $(j)$ aqueous solution acidified with trifluoromethanesulfonic acid.

and the refined structure parameters are given in Table 3. The $\mathrm{Cu}-\mathrm{O}_{\mathrm{eq}}$ bond distances in the dmf- and def-solvated copper(II) ions are slightly longer than in the dma, dea, dmp, and dep copper(II) solvates (Table 3). The $\mathrm{Cu}-\mathrm{O}-\mathrm{C}$ angles in the $\mathrm{dmf}$ and def copper(II) solvates, $124(1)^{\circ}$, are significantly smaller than the dma, dea, dmp and dep angles, $130(1)^{\circ}$ (Table 3). This pattern is also seen in the solid structures of dmf- and dma-solvated copper(II) ions with mean 
Table 3. Summary of Refinements of EXAFS Data Using a Noncentrosymmetric Tetragonally Elongated Octahedral Geometry of the Solvated Copper(II) ion in Water (aq), Methanol (M), N,N-Dimethylformamide (dmf), $N, N$-Dimethylacetamide (dma), $N, N$-Dimethylpropionamide (dmp), $N, N$-Diethylformamide (def), $N, N$-Dimethylacetamide(dea), $N, N$-Dimethylpropionamide (dep), $N, N^{\prime}$-Dimethylpropyleneurea (dmpu), and $N, N, N^{\prime}, N^{\prime}$-Tetramethylurea $(\mathrm{tmu})^{a}$

\begin{tabular}{|c|c|c|c|c|c|c|c|c|c|c|}
\hline & water & methanol & $\mathrm{dmf}$ & def & dma & dea & $\mathrm{dmp}$ & dep & dmpu & tmu \\
\hline$d\left(\mathrm{Cu}-\mathrm{O}_{\mathrm{eq}}\right)$ & $1.957(3)$ & $1.975(3)$ & $1.963(3)$ & $1.967(3)$ & $1.956(3)$ & $1.956(3)$ & $1.952(3)$ & $1.951(3)$ & $1.939(3)$ & $1.935(3)$ \\
\hline$\sigma^{2}\left(\mathrm{Cu}-\mathrm{O}_{\mathrm{eq}}\right)$ & $0.0055(3)$ & $0.0064(3)$ & $0.0061(3)$ & $0.0058(3)$ & $0.0060(3)$ & $0.0061(3)$ & $0.0062(3)$ & $0.0058(3)$ & $0.0057(3)$ & $0.0060(3)$ \\
\hline$n\left(\mathrm{Cu}-\mathrm{O}_{\mathrm{eq}}\right)$ & 4 & 4 & 4 & 4 & 4 & 4 & 4 & 4 & 4 & 4 \\
\hline$d\left(\mathrm{Cu}-\mathrm{O}_{\mathrm{axl}}\right)$ & $2.14(2)$ & $2.202(8)$ & $2.178(8)$ & $2.186(3)$ & $2.14(1)$ & & $2.17(1)$ & $2.16(3)$ & $2.11(4)$ & \\
\hline$\sigma^{2}\left(\mathrm{Cu}-\mathrm{O}_{\mathrm{axl}}\right)$ & $0.007(2)$ & $0.0069(8)$ & $0.0068(8)$ & $0.007(1)$ & $0.007(2)$ & & $0.007(2)$ & $0.011(2)$ & $0.014(4)$ & \\
\hline$n\left(\mathrm{Cu}-\mathrm{O}_{\mathrm{axl}}\right)$ & 1 & 1 & 1 & 1 & 1 & & 1 & 1 & 1 & \\
\hline$d\left(\mathrm{Cu}-\mathrm{O}_{\mathrm{ax} 2}\right)$ & $2.32(2)$ & $2.34(1)$ & $2.33(1)$ & $2.34(1)$ & $2.32(2)$ & & $2.34(2)$ & $2.30(4)$ & $2.27(4)$ & \\
\hline$\sigma^{2}\left(\mathrm{Cu}-\mathrm{O}_{\mathrm{ax} 2}\right)$ & $0.009(2)$ & $0.007(2)$ & $0.008(1)$ & $0.007(2)$ & $0.010(2)$ & & $0.014(3)$ & $0.014(5)$ & $0.013(5)$ & \\
\hline$n\left(\mathrm{Cu}-\mathrm{O}_{\mathrm{ax} 2}\right)$ & 1 & 1 & 1 & 1 & 1 & & 1 & 1 & 1 & \\
\hline$d\left(\mathrm{MS}\left(\mathrm{CuO}_{4}\right)\right)$ & 3.914 & 3.951 & 3.926 & 3.935 & 3.912 & 3.913 & 3.904 & 3.902 & 3.878 & 3.870 \\
\hline$\sigma^{2}\left(\mathrm{MS}\left(\mathrm{CuO}_{4}\right)\right)$ & $0.012(3)$ & $0.011(3)$ & $0.012(2)$ & $0.012(2)$ & $0.009(3)$ & $0.009(2)$ & $0.011(4)$ & $0.009(4)$ & $0.009(3)$ & $0.014(5)$ \\
\hline$n\left(\mathrm{MS}\left(\mathrm{CuO}_{4}\right)\right)$ & $3 * 4$ & $3 * 4$ & $3 * 4$ & $3 * 4$ & $3 * 4$ & $3 * 4$ & $3 * 4$ & $3 * 4$ & $3 * 4$ & $3 * 4$ \\
\hline$d(\mathrm{Cu}-\mathrm{C})$ & & $3.03(2)$ & $2.855(7)$ & $2.859(9)$ & $2.93(1)$ & $2.92(1)$ & $2.94(1)$ & $2.94(1)$ & $2.85(1)$ & $2.91(2)$ \\
\hline$\sigma^{2}(\mathrm{Cu}-\mathrm{C})$ & & $0.013(2)$ & $0.009(4)$ & $0.009(1)$ & $0.011(1)$ & $0.011(1)$ & $0.012(1)$ & $0.011(2)$ & $0.014(2)$ & $0.013(3)$ \\
\hline$n(\mathrm{Cu}-\mathrm{C})$ & & 4 & 4 & 4 & 4 & 4 & 4 & 4 & 4 & 4 \\
\hline$d(\mathrm{Cu}-\mathrm{O}-\mathrm{C})$ & & $3.18(4)$ & $3.03(2)$ & $3.03(3)$ & $3.07(2)$ & $3.06(2)$ & $3.07(1)$ & $3.08(1)$ & $3.02(4)$ & $3.09(1)$ \\
\hline$\sigma^{2}(\mathrm{Cu}-\mathrm{O}-\mathrm{C})$ & & $0.026(5)$ & $0.011(3)$ & $0.013(2)$ & $0.010(1)$ & $0.011(2)$ & $0.010(1)$ & $0.009(1)$ & $0.009(2)$ & $0.011(1)$ \\
\hline$n(\mathrm{Cu}-\mathrm{O}-\mathrm{C})$ & & 8 & 8 & 8 & 8 & 8 & 8 & 8 & 8 & 8 \\
\hline$\angle \mathrm{Cu}-\mathrm{O}-\mathrm{C}$ & & $127.9(5)$ & $123.9(3)$ & $123.9(3)$ & $130.9(4)$ & & $130.3(4)$ & $132.2(6)$ & $131.8(6)$ & \\
\hline$d(\mathrm{Cu}-\mathrm{N})$ & & & $3.99(1)$ & $3.99(2)$ & $4.00(2)$ & $4.01(2)$ & $4.01(2)$ & $4.01(3)$ & & \\
\hline$\sigma^{2}(\mathrm{Cu}-\mathrm{N})$ & & & $0.009(4)$ & $0.010(2)$ & $0.010(2)$ & $0.010(2)$ & $0.009(3)$ & $0.010(3)$ & & \\
\hline$n(\mathrm{Cu}-\mathrm{N})$ & & & 4 & 4 & 4 & 4 & 4 & 4 & & \\
\hline$d(\mathrm{Cu}-\mathrm{N}-\mathrm{C})$ & & & $4.27(4)$ & $4.29(4)$ & $4.24(5)$ & $4.25(4)$ & $4.24(7)$ & $4.22(6)$ & & \\
\hline$\sigma^{2}(\mathrm{Cu}-\mathrm{N}-\mathrm{C})$ & & & $0.006(4)$ & $0.006(4)$ & $0.012(5)$ & $0.012(4)$ & $0.015(9)$ & $0.012(7)$ & & \\
\hline$n(\mathrm{Cu}-\mathrm{N}-\mathrm{C})$ & & & 8 & 8 & 8 & 8 & 8 & 8 & & \\
\hline$S_{0}^{2}$ & $0.93(4)$ & $1.09(4)$ & $1.10(4)$ & $1.07(4)$ & $1.09(4)$ & $1.10(4)$ & $1.10(4)$ & $0.95(5)$ & $0.92(3)$ & $0.97(4)$ \\
\hline$E_{0}$ & $8989.7(5)$ & $8990.0(5)$ & $8989.8(5)$ & $8991.1(5)$ & $8989.9(5)$ & $8988.9(5)$ & $8989.5(5)$ & $8989.5(5)$ & $8988.2(5)$ & $8987.3(5)$ \\
\hline$F$ & 18.14 & 18.26 & 16.13 & 19.73 & 14.95 & 12.91 & 17.09 & 16.80 & 20.93 & 23.85 \\
\hline
\end{tabular}

${ }^{a}$ Definitions: distance; $d / \AA$, Debye-Waller coefficient, $\sigma^{2} / \AA^{2}$; number of distances, $n$; amplitude reduction factor, $S_{0}^{2}$; threshold energy, $E_{0} / \mathrm{eV}$; weighted $F$ factor, $F$. Estimated errors within parentheses includes the statistical errors from the refinements and estimated experimental errors. Parameters without following parentheses have been fixed. ${ }^{b}$ The linear multiple scattering distance with in the $\mathrm{CuO}_{4}$ equatorial plane has been linked to the $\mathrm{Cu}-\mathrm{O}$ bond distance.

$\mathrm{Cu}-\mathrm{O}-\mathrm{C}$ bond angles of 124.5 and $129.6^{\circ}$, respectively. ${ }^{71-77}$ With an alkyl group binding to the amide carbon, the electron density on the oxygen becomes slightly smaller and the binding character slightly more electrostatic in comparison to formamides with a hydrogen binding to the amide carbon. The fits of raw EXAFS data and the Fourier transform of the methanol and amide solvent copper(II) solvates are shown in Figures 4 and 5, respectively, and the refined structure parameters are given in Table 3.

Test of Different Models in the Refinements of EXAFS

Data. The refined structure parameters of the solvated copper(II) ions using three models, a tetragonally elongated square pyramid and centrosymmetric and noncentrosymmetric tetragonally elongated octahedra, need to be compared. The solid compounds have all a well-defined composition, which suggests that a five-coordinate complex can be excluded. A comparison of the two Jahn-Teller distorted models shows that the mean $\mathrm{Cu}-\mathrm{O}_{\mathrm{ax}}$ bond distance in the centrosymmetric model becomes fairly close to the average of the two $\mathrm{Cu}-\mathrm{O}_{\mathrm{ax}}$ bond distances in the noncentrosymmetric model (Table 2 and Table S6). Furthermore, the Debye-Waller coefficients, $\sigma^{2}$, become unreasonably large, strongly indicating that the distance consists of at least two separated distances. Applying the noncentrosymmetric model with two well-separated $\mathrm{Cu}-$
$\mathrm{O}_{\mathrm{ax}}$ bond distances results in the refined Debye-Waller coefficients are within the expected values for bond distances of this kind, $0.005-0.009 \AA^{-1}$. This strongly indicates that the $\mathrm{Cu}-\mathrm{O}_{\mathrm{ax}}$ bond distances in the studied solid hydrates and solvates are different and are well separated with a difference of 0.15-0.20 ̊ (Tables 2 and 3).

For the studied solutions the tetragonally elongated squarepyramidal model has to be included as well in this comparison. Applying the centrosymmetric octahedral model results in very large Debye-Waller coefficients for the $\mathrm{Cu}-\mathrm{O}_{\mathrm{ax}}$ bond distances as found in the solid hydrate samples discussed above (Table S8a). When the square-pyramidal model is applied, the $\mathrm{Cu}-\mathrm{O}_{\mathrm{ax}}$ bond distance becomes close to the value obtained by using the centrosymmetric octahedral model but the Debye-Waller coefficients becomes significantly smaller, 0.009-0.014 $\AA^{2}$ (Table S8b), but still of an order indicating a wide bond distance distribution for a single bond.

The pattern of bond distances and Debye-Waller coefficients and the fact that the EXAFS spectra of solid $\left[\mathrm{Cu}\left(\mathrm{H}_{2} \mathrm{O}\right)_{6}\right]\left(\mathrm{ClO}_{4}\right)_{2}, \mathrm{Cu}\left(\mathrm{NO}_{3}\right)_{2} \cdot 2.5 \mathrm{H}_{2} \mathrm{O},\left[\mathrm{Cu}\left(\mathrm{H}_{2} \mathrm{O}\right)_{6}\right]$ $\left(\mathrm{BrO}_{3}\right)_{2}$, and $\left[\mathrm{Cu}\left(\mathrm{H}_{2} \mathrm{O}\right)_{6}\right] \mathrm{SiF}_{6}$ and the aqueous solutions of copper(II) superimpose (Figure 1) strongly indicate the hydrated copper(II) ion and the solvated copper(II) ion in methanol and the six amide solvents bind six solvent molecules 
in a noncentrosymmetric tetragonally elongated octahedral geometry. This model is in full agreement with the observation using EPR that the hydrated copper(II) ion is noncentrosymmetric in aqueous solution ${ }^{6,7}$ and is in full agreement with the EXAFS studies reported by Frank et al. ${ }^{13,22,25}$ The survey of structure determinations of solid compounds containing a hexaaquacopper(II) ion or a pentaaqua(O-ligand)copper(II) complex described in the Introduction strongly indicates that individual copper(II) complexes in fact are six-coordinate and noncentrosymmetric. It is therefore very important to apply a non-lattice-dependent method such as EXAFS to determine the structures of such compounds.

Structure of the Solvated Copper(II) lon in dmpu and tmu Studied by EXAFS. In the solvents which are space demanding upon coordination, dmpu and tmu, the axial positions are protected by the ligands in the equatorial positions (see below), resulting in square-planar complexes. It was not possible to locate any more solvent molecules within a reasonable bond distance. The $\mathrm{Cu}-\mathrm{O}$ bond distances in the dmpu- and tmu-solvated copper(II) ions are significantly shorter, 1.939(3) and 1.935(3) $\AA$, respectively, than the shortest $\mathrm{Cu}-\mathrm{O}_{\text {eq }}$ bond distances in the hexasolvated copper(II) ions, 1.954(3) $\AA$, for acetamide and propionamide (Table 3) but are in agreement with four-coordinated copper(II) complexes with oxygen donor ligands (Table S3). The copper(II) trifluoromethanesulfonate solutions in dmpu and tmu have an intense dark green color due to a strong absorption band in the UV region and another at around 800 $\mathrm{nm}$, both tailing into the visible region (Figure S1).

Structure of the dmpu-Solvated Copper(II) Ion in dmpu Solution Studied by LAXS. The radial distribution function of a LAXS study of a $0.8 \mathrm{~mol} \mathrm{dm}^{-3}$ copper(II) trifluoromethanesulfonate solution shows a peak just below 2 $\AA$ assigned to the $\mathrm{Cu}-\mathrm{O}$ bond distance and refined to 1.93(2) $\AA$ (Figure 6). The LAXS model used includes interatomic interactions between the copper(II) ion and the solvating ligands and interactions within the solvent molecules and within the anions.

Crystal Structure of $\left[\mathrm{Cu}(\mathrm{dmpu})_{4}\right]\left(\mathrm{CF}_{3} \mathrm{SO}_{3}\right)_{2} \cdot \mathrm{dmpu}$ (1). The crystal structure of $\mathbf{1}$ consists of tetrakis $\left(N, N^{\prime}\right.$ dimethylpropyleneurea)copper(II) and trifluoromethanesulfonate ions, and with an additional noncoordinated $N, N^{\prime}$ dimethylpropyleneurea molecule in the lattice. The almost planar dmpu molecules are stacked perpendicular to the equatorial plane with two crystallographically independent ligands having $\mathrm{Cu}-\mathrm{O}$ bond distances of $1.900(3)$ and 1.902(3) $\AA$, with $\mathrm{Cu}-\mathrm{O}-\mathrm{C}$ angles of $127.3(3)$ and $129.5(3)^{\circ}$, respectively, forming a regular square-planar coordination (Figure 7). The low quality of the crystal made it necessary to add additional loose structural restraints to obtain sound results. For both of the ligand molecules, it was possible to refine two alternate positions, C14A/B and C24A/B, for the middle propylene carbon with partial occupancies at $73 / 27$ and $53 / 47 \%$, respectively, whereas the other ligand molecule showed the typical half-chair formation partial distribution refinement of its carbon, C14. The copper(II) methyl carbon distances $\mathrm{Cu}-\mathrm{C}$ are approximately $3.7(1) \AA$, at roughly $45^{\circ}$ from the flat $\mathrm{CuO}_{4}$ plane. Bond distances and angles in the trifluoromethanesulfonate ions are in agreement with those in previous studies, but due to disorder alternative positions were added. ${ }^{4}$ The noncoordinated dmpu oxygen is $7.8 \AA$ away from the copper(II) ion. Selected crystallographic data are given in Table 2, and selected bond distances and angles are given in
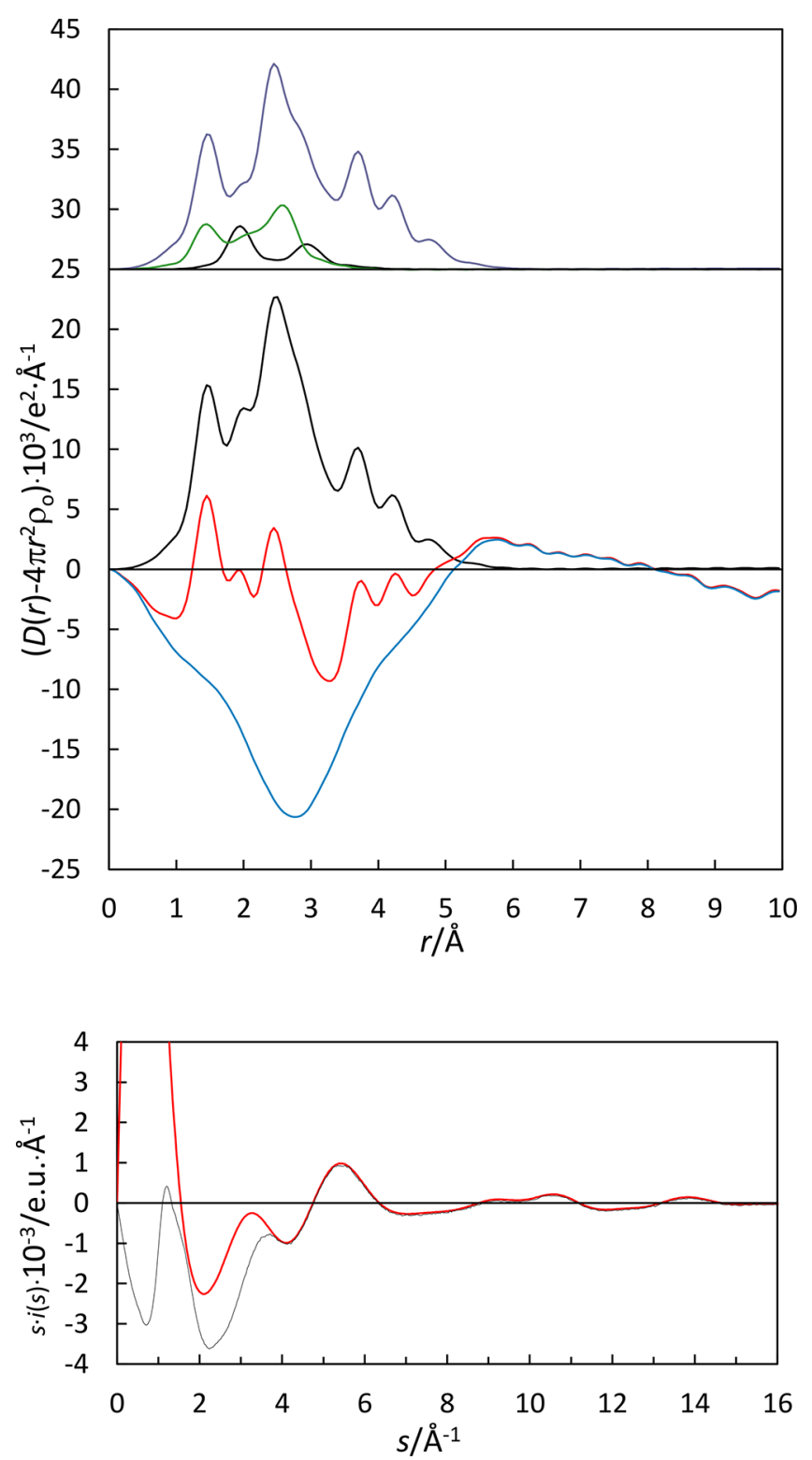

Figure 6. (Top) LAXS radial distribution curves for a $0.8 \mathrm{~mol} \mathrm{dm}^{-3}$ copper(II) trifluoromethanesulfonate dmpu (top) separate model contributions (offset 14) of the tetrakis(dmpu)copper(II) complex (solid line), the trifluoromethanesulfonate ion (dashed line), and dmpu solvent (dotted line); (middle) experimental RDF with $D(r)$ $-4 p r^{2} \rho_{0}$ (solid line), sum of model contributions (dashed line), and difference (dotted line); (bottom) reduced LAXS intensity functions $s . i(s)$ (thin line) and model $s . i_{\text {calc }}(s)$ (thick line).

Table 4. By a view perpendicular to the $\mathrm{CuO}_{4}$ plane of the tetrakis $(N, N$ '-dimethylpropyleneurea)copper(II) ion it is clearly seen that the dmpu methyl groups effectively hinder access of ligands to the axial positions. Furthermore, the methyl groups near the axial position have no bonding properties to the copper(II) ion.

Summary of the Coordination Chemistry of the Hydrated and Solvated Copper(II) Ions. Even though a large majority of the hexaaquacopper(II) complexes reported in the solid state are found to be centrosymmetric (Table S1), it has not been possible to confirm this with the latticeindependent EXAFS method in this study. It therefore seems very likely that the direction of the short and long axial $\mathrm{Cu}-\mathrm{O}$ 


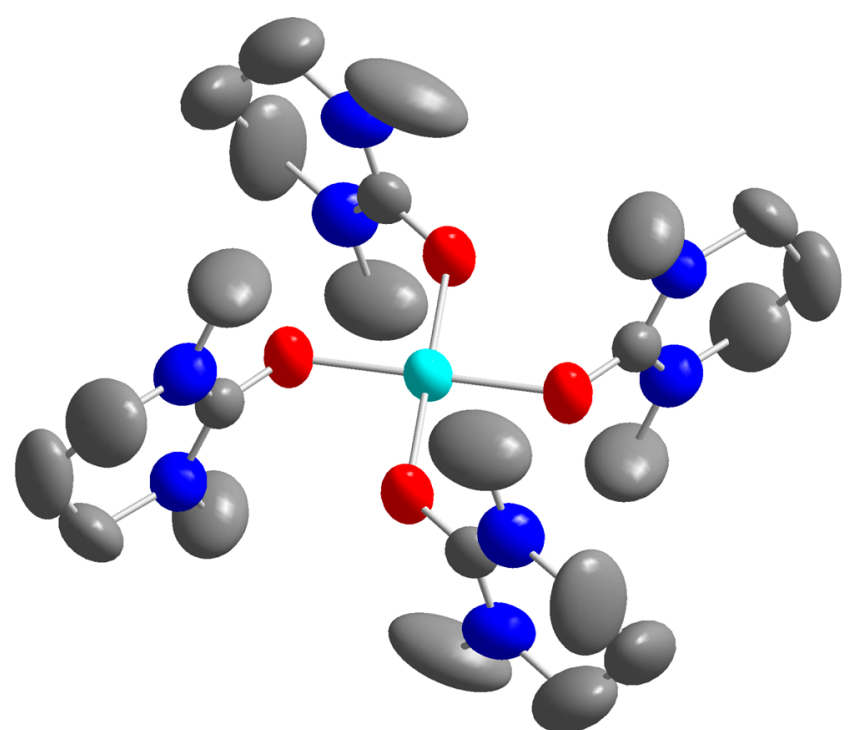

Figure 7. Structure of the tetrakis(dmpu)copper(II) unit in $\mathbf{1}$. Ellipsoids for all non-hydrogen atoms are set at $40 \%$ probability.

Table 4. Selected Bond Distances ( $\AA$ ) and Angles (deg) from the Crystal Structure Determination of Solid $\left[\mathrm{Cu}(\mathrm{dmpu})_{4}\right]\left(\mathrm{CF}_{3} \mathrm{SO}_{3}\right)_{2} \cdot \mathrm{dmpu}$

\begin{tabular}{|c|c|c|c|}
\hline bond distance & & bond angle & \\
\hline $\mathrm{Cu}-\mathrm{O} 1$ & $1.900(3)$ & $\mathrm{O} 1-\mathrm{Cu}-\mathrm{O} 2$ & $90.15(14)$ \\
\hline $\mathrm{Cu}-\mathrm{O} 2$ & $1.902(3)$ & $\mathrm{O} 1-\mathrm{Cu}-\mathrm{O}_{2}$ & $89.86(14)$ \\
\hline
\end{tabular}

bond distances can be randomly distributed in solid compounds, resulting in a mean structure with higher symmetry in comparison to the symmetry of the individual complexes. This seems also to be the case for hexaaquacopper(II) ions reported to have a regular or somewhat irregular octahedral geometry, as some of these have been shown to have the expected Jahn-Teller distortion (vide supra). Of the complexes without a center of symmetry or with the center of symmetry not on copper in the $\left[\mathrm{Cu}\left(\mathrm{H}_{2} \mathrm{O}\right)_{6}\right]^{2+}$ complex, only a few display almost similar $\mathrm{Cu}-\mathrm{O}_{\mathrm{ax}}$ distances, while the remaining structures display significant different $\mathrm{Cu}-\mathrm{O}_{\mathrm{ax}}$ distances (Table S1). Furthermore, all reported [Cu$\left(\mathrm{H}_{2} \mathrm{O}\right)_{5}(\mathrm{O}$-donor ligand)] complexes with Jahn-Teller distortion display significantly different $\mathrm{Cu}-\mathrm{O}_{\mathrm{ax}}$ distances independent of whether the O-donor ligand is in equatorial or axial position (Table S2). The high $k$ range EXAFS data collected in this study and by Frank et al..$^{22}$ allows a high resolution of distances. Using a model with two different axial $\mathrm{Cu}-\mathrm{O}_{\mathrm{ax}}$ bond distances resulted in stable refinements independent of the system. This includes all solvents where copper(II) is six-coordinate, all studied solvents except tmu and dmpu, and the solids $\left[\mathrm{Cu}\left(\mathrm{H}_{2} \mathrm{O}\right)_{6}\right]\left(\mathrm{ClO}_{4}\right)_{2},\left[\mathrm{Cu}\left(\mathrm{H}_{2} \mathrm{O}\right)_{6}\right]$ $\left(\mathrm{BrO}_{3}\right)_{2},\left[\mathrm{Cu}\left(\mathrm{H}_{2} \mathrm{O}\right)_{6}\right] \mathrm{SiF}_{6}, \mathrm{Cu}\left(\mathrm{NO}_{3}\right)_{2} \cdot 2 \cdot 5 \mathrm{H}_{2} \mathrm{O}$, and $\mathrm{CuSO}_{4}$. $5 \mathrm{H}_{2} \mathrm{O}$. The similar UV-vis spectra of the hydrated copper(II) ion in aqueous solution and the solvated copper(II) ion in methanol, dmf, def, dma, dea, dmp, and dep further support a similar configuration (Figure S1).

\section{CONCLUSIONS}

The structure of the solvated copper(II) ion in 10 oxygen donor solvents with similar bonding characteristics but with different space-demanding properties on coordination have been studied by EXAFS spectroscopy. In the solvents with large space-demanding properties on coordination, dmpu and tmu, copper(II) is shown to have a square-planar configuration with mean $\mathrm{Cu}-\mathrm{O}$ bond distances of 1.93(2) $\AA$. The best fits in the other solvents are obtained with a noncentrosymmetric tetragonally elongated octahedral model with different axial $\mathrm{Cu}-\mathrm{O}$ bond distances with mean $\mathrm{Cu}-\mathrm{O}_{\mathrm{eq}}, \mathrm{Cu}-\mathrm{O}_{a x 1}$, and $\mathrm{Cu}-$ $\mathrm{O}_{\mathrm{ax} 2}$ bond distances of ca. 1.96, 2.15, and $2.32 \AA$, respectively. This model is in full agreement with that proposed by Frank et al. for the hydrated copper(II) ion from EXAFS studies. ${ }^{13,22,25}$ However, from the point-of-view of EXAFS data other configurations such as tetragonally elongated square pyramidal cannot be ruled out. EPR studies have shown that the hydrated copper(II) ion in aqueous solution is noncentrosymmetric. ${ }^{7,8}$ A large number of number of theoretical simulations have concluded that $\left[\mathrm{Cu}\left(\mathrm{H}_{2} \mathrm{O}\right)_{5}\right]^{2+}$ and $\left[\mathrm{Cu}\left(\mathrm{H}_{2} \mathrm{O}\right)_{5} \cdots \mathrm{H}_{2} \mathrm{O}\right]^{2+}$ configurations are more stable in aqueous solution in comparison to the centrosymmetric Jahn-Teller distortedoctahedral configuration. ${ }^{11,12,15,16,21,23}$ An in-depth survey of solid-state structures containing isolated hydrated copper(II) ions has shown that hexaaquacopper(II) complexes crystallizing in noncentrosymmetric space groups as well as in centrosymmetric space groups where the center of symmetry is not on the copper in the $\left[\mathrm{Cu}\left(\mathrm{H}_{2} \mathrm{O}\right)_{6}\right]^{2+}$ ion display significantly different $\mathrm{Cu}-\mathrm{O}$ bond distances in the axial positions (Table S1). Furthermore, all of the $\left[\mathrm{Cu}\left(\mathrm{H}_{2} \mathrm{O}\right)_{5}(\mathrm{O}\right.$ ligand)] complexes displaying Jahn-Teller distortion show the same splitting in the $\mathrm{Cu}-\mathrm{O}_{\mathrm{ax}}$ bond distances independent of the position of the O-ligand (Table S2). EXAFS spectra of aqueous copper(II) solutions and the solids $\left[\mathrm{Cu}\left(\mathrm{H}_{2} \mathrm{O}\right)_{6}\right]$ $\left(\mathrm{ClO}_{4}\right)_{2}, \quad\left[\mathrm{Cu}\left(\mathrm{H}_{2} \mathrm{O}\right)_{6}\right]\left(\mathrm{BrO}_{3}\right)_{2}$, and $\left[\mathrm{Cu}\left(\mathrm{H}_{2} \mathrm{O}\right)_{6}\right] \mathrm{SiF}_{6}$ are superimposable, strongly indicating that the hydrated copper(II) ions in these salts have the same or very similar configurations around copper as in aqueous solution. This is in spite of the fact that the crystallographic studies report centrosymmetric structures with a regular octahedral configuration for the last two complexes. This strongly indicates that copper(II) complexes reported to be centrosymmetric in the solid state are mean structures of noncentrosymmetric entities with random orientation of the copper(II) complex in the individual unit cells. A summary of the present information from different methods and publications is as follows.

- The hydrated copper(II) ion in aqueous solution is sixcoordinate with a noncentrosymmetric tetragonally elongated octahedral geometry, and the difference in the $\mathrm{Cu}-\mathrm{O}_{\mathrm{ax}}$ bond distances is on the order of $0.2 \AA$,

- The solvated copper(II) ion in the seven organic oxygen donor solvents without steric demands on coordination have the same configuration in solution as that of the hydrated copper(II) ion.

- The solvated copper(II) ion has a four-coordinate square-planar configuration in space-demanding solvents on coordination, as the axial positions become inaccessible.

- It seems very likely that all six-coordinate copper(II) complexes reported to be centrosymmetric in the solid state have a noncentrosymmetric tetragonally elongated octahedral configuration with a random orientation of at least the axial ligands, but as crystallography gives the mean of all unit cells in the solid, the mean structure becomes centrosymmetric. 


\section{ASSOCIATED CONTENT}

\section{SI Supporting Information}

The Supporting Information is available free of charge at https://pubs.acs.org/doi/10.1021/acs.inorgchem.0c00403.

Summary of reported solid-state structures with hydrated copper(II) ions, complexes with the composition $\left[\mathrm{Cu}\left(\mathrm{H}_{2} \mathrm{O}\right)_{5}(\mathrm{O}\right.$-ligand $\left.)\right]$, and four- and five-coordinate copper(II) complexes with oxygen donor ligands, compositions of the studied solutions, structure parameters obtained in alternative models and unit cell parameters and $\mathrm{Cu}-\mathrm{O}$ bond distances in $\left[\mathrm{Cu}\left(\mathrm{H}_{2} \mathrm{O}\right)_{6}\right]$ $\left(\mathrm{ClO}_{4}\right)_{2}, \mathrm{Cu}\left(\mathrm{NO}_{3}\right)_{2} \cdot 2.5 \mathrm{H}_{2} \mathrm{O}$, and $\mathrm{CuSO}_{4} \cdot 5 \mathrm{H}_{2} \mathrm{O}$, UVvis spectra of copper(II) in the studied solvents, and a comparison of EXAFS spectra and corresponding Fourier transforms calculated from reported solid and experimental structures (PDF)

\section{Accession Codes}

CCDC 1953489 contains the supplementary crystallographic data for this paper. These data can be obtained free of charge via www.ccdc.cam.ac.uk/data_request/cif, or by emailing data_request@ccdc.cam.ac.uk, or by contacting The Cambridge Crystallographic Data Centre, 12 Union Road, Cambridge CB2 1EZ, UK; fax: +44 1223336033.

\section{AUTHOR INFORMATION}

\section{Corresponding Author}

Ingmar Persson - Department of Molecular Sciences, Swedish University of Agricultural Sciences, SE-750 07 Uppsala,

Sweden; orcid.org/0000-0002-1061-7536;

Email: ingmar.persson@slu.se

\section{Authors}

Daniel Lundberg - Department of Molecular Sciences, Swedish University of Agricultural Sciences, SE-750 07 Uppsala, Sweden

Éva G. Bajnóczi - Department of Molecular Sciences, Swedish University of Agricultural Sciences, SE-750 07 Uppsala, Sweden; (1) orcid.org/0000-0002-8469-5887

Konstantin Klementiev - MAX IV Laboratory, Lund University, SE-221 00 Lund, Sweden

Justus Just - MAX IV Laboratory, Lund University, SE-22100 Lund, Sweden

Kajsa G. V. Sigfridsson Clauss - MAX IV Laboratory, Lund University, SE-221 00 Lund, Sweden

Complete contact information is available at:

https://pubs.acs.org/10.1021/acs.inorgchem.0c00403

\section{Notes}

The authors declare no competing financial interest.

\section{ACKNOWLEDGMENTS}

We gratefully acknowledge the Swedish Research Council for financial support. The MAX IV laboratory, Lund University, is acknowledged for allocation of beam time during the commissioning period for these studies. Dr. Andrew Ken Inge and Mr. Erik Svensson Grape, Department of Materials and Environmental Chemistry, Stockholm University, are acknowledged for the determination of unit cell parameters of the solid compounds used in this study.

\section{REFERENCES}

(1) Orgel, L. E. An introduction to transition metal chemistry ligandfield theory, 2nd ed.; Butler \& Tanner: London, Great Britain, 1966, and references therein.

(2) Figgis, B. N.; Hitchman, M. A. Ligand field theory and its application; Wiley: 2000, and references therein.

(3) Bersuker, I. Electronic structure and properties of transition metal compounds; Wiley-Interscience: New York, 1996, and references therein.

(4) Allen, F. H. The Cambridge Structural Database: a quarter of a million crystal structures and rising. Acta Crystallogr., Sect. B: Struct. Sci. 2002, 58, 380-388.

(5) Inorganic Crystal Structure Database 1.4.6 (release: 2019-2); FIZ/ NIST.

(6) Hathaway, B. J. Coord. Chem. Rev. 1981, 35, 211-252.

(7) Peisach, J.; Mims, W. B. Deviations from centrosymmetry in some simple $\mathrm{Cu}^{2++}$ complexes. Chem. Phys. Lett. 1976, 37, 307-310.

(8) Peisach, J.; Mims, W. B. Linear electric-field effect in stellacyanine, azurin, and some simple model compounds. Eur. J. Biochem. 1978, 84 (8), 207-214.

(9) Pasquarello, A.; Petri, I.; Salmon, P. S.; Parisel, O.; Car, R.; Toth, E.; Powell, D. H.; Fischer, H. E.; Helm, L.; Merbach, A. E. First solvation shell of the $\mathrm{Cu}(\mathrm{II})$ aqua ion: Evidence for fivefold coordination. Science 2001, 291, 856-859.

(10) Benfatto, M.; D’Angelo, P.; Della Longa, S.; Pavel, N. V. Evidence of distorted fivefold coordination of the $\mathrm{Cu}^{2++}$ aqua ion from an x-ray-absorption spectroscopy quantitative analysis. Phys. Rev. B: Condens. Matter Mater. Phys. 2002, 65, 174205.

(11) Schwenk, C. F.; Rode, B. M. New insights into the Jahn-Teller effect through ab initio quantum-mechanical/molecular mechanical dynamics simulations of $\mathrm{Cu}^{\mathrm{II}}$ in water. ChemPhysChem 2003, 4, 931943.

(12) Schwenk, C. F.; Rode, B. M. Extended ab initio quantum mechanical/molecular mechanical molecular dynamics simulations of hydrated $\mathrm{Cu}^{2++}$. J. Chem. Phys. 2003, 119, 9523-9531.

(13) Frank, P.; Benfatto, M.; Szilagyi, R. K.; D’Angelo, P.; Della Longa, S.; Hodgson, K. O. The solution structure of $[\mathrm{Cu}(\mathrm{aq})]^{2++}$ and its implications for rack-induced bonding in blue copper protein active. Inorg. Chem. 2005, 44, 1922-1933.

(14) Chaboy, J.; Munoz-Paez, A.; Merkling, P. J.; Marcos, E. S. The hydration of $\mathrm{Cu}^{2++}$ : Can the Jahn-Teller effect be detected in liquid solution? J. Chem. Phys. 2006, 124, 064509.

(15) Bryantsev, V. S.; Diallo, M. S.; van Duin, A. C. T.; Goddard, W. A., III Hydration of copper(II): New insights from density functional theory and the COSMO solvation model. J. Phys. Chem. A 2008, 112, 9104-9112.

(16) de Almeida, K. J.; Murugan, N. A.; Rinkevicius, Z.; Hugosson, H. W.; Vahtras, O.; Agren, H.; Cesar, A. Conformations, structural transitions and visible near-infrared absorption spectra of four-, fiveand six-coordinated $\mathrm{Cu}(\mathrm{II})$ aqua complexes. Phys. Chem. Chem. Phys. 2009, 11, 508-519.

(17) Liu, X.; Lu, X.; Meijer, E. J.; Wang, R. Hydration mechanisms of $\mathrm{Cu}^{2++}$ : tetra-, penta- or hexa-coordinated? Phys. Chem. Chem. Phys. 2010, 12, 10801-10804.

(18) Smirnov, P. R; Trostin, V. N. Structural Parameters of $\mathrm{Cu}^{2++}$ Aqua Complexes in Aqueous Solution of Its Salts. Russ. J. Gen. Chem. 2009, 79, 1591-1599.

(19) Bowron, D. T.; Amboage, M.; Boada, R.; Freeman, A.; Hayama, S.; Diaz-Moreno, S. The hydration structure of $\mathrm{Cu}^{2++}$ : more tetrahedral than octahedral? RSC Adv. 2013, 3, 17803-17812.

(20) Bowron, D. T; Moreno, S. D. The structure of water in solutions containing di- and trivalent cations by empirical potential structure refinement. J. Phys.: Condens. Matter 2013, 25, 454213.

(21) Moin, S. T.; Hofer, T. S.; Weiss, A. K. H.; Rode, B. M. Dynamics of ligand exchange mechanism at $\mathrm{Cu}$ (II) in water: $\mathrm{An} \mathrm{ab}$ initio quantum mechanical charge field molecular dynamics study with extended quantum mechanical region. J. Chem. Phys. 2013, 139, 014503. 
(22) Frank, P.; Benfatto, M.; Qayyam, M.; Hedman, B.; Hogdson, K. $\mathrm{O}$. A high-resolution XAS study of aqueous $\mathrm{Cu}(\mathrm{II})$ in liquid and frozen solutions: Pyramidal, polymorphic, and non-centrosymmetric. J. Chem. Phys. 2015, 142, 084310.

(23) Chillemi, G.; Pace, E.; D’Abramo, M.; Benfatto, M. Equilibrium between 5-and 6-Fold Coordination in the First Hydration Shell of $\mathrm{Cu}(\mathrm{II})$. J. Phys. Chem. A 2016, 120, 3958-3965.

(24) Galván-Garcia, E. A.; Agacino-Valdés, E.; Franco-Pérez, M.; Gómez-Balderas, R. $\left[\mathrm{Cu}\left(\mathrm{H}_{2} \mathrm{O}\right)_{\mathrm{n}}\right]^{2++}(\mathrm{n}=1-6)$ complexes in solution phase: a DFT hierarchical study. Theor. Chem. Acc. 2017, 136, 29.

(25) Frank, P.; Benfatto, M.; Qayyum, M. $[\mathrm{Cu}(\mathrm{aq})]^{2++}$ is structurally plastic and the axially elongated octahedron goes missing. J. Chem. Phys. 2018, 148, 204302.

(26) Zitolo, A.; Chillemi, G.; D’Angelo, P. X-ray absorption study of the solvation structure of $\mathrm{Cu}^{2++}$ in methanol and dimethyl sulfoxide. Inorg. Chem. 2012, 51, 8827-8833.

(27) D'Angelo, P.; Migliorati, V. Solvation Structure of $\mathrm{Zn}^{2++}$ and $\mathrm{Cu}^{2++}$ in Acetonitrile: A Combined EXAFS and XANES Study. J. Phys. Chem. B 2015, 119, 4061-4067.

(28) Laborda, S.; Clerac, R.; Anson, C. E.; Powell, A. K. Intra and intermolecular magnetic interactions in a series of dinuclear $\mathrm{Cu}(\mathrm{II}) /$ hxta complexes $\left\{\mathrm{H}(5) \mathrm{hxta}==\mathrm{N}, \mathrm{N}^{\prime}\right.$-(2-hydroxy-1,3-xylylene)-bis(N-carboxymethylglycine)\}: Correlation of magnetic properties with geometry. Inorg. Chem. 2004, 43, 5931-5943.

(29) Xiong, K.; Jiang, F.; Wu, M.; Gai, Y.; Chen, Q.; Zhang, S.; Ma, J.; Han, D.; Hong, M. Two novel chains based on capsules supported by water-soluble calixarenes and metal complexes. J. Solid State Chem. 2012, 192, 215-220.

(30) Ma, Y.-S.; Wang, T.-W.; Li, Y.-Z.; Zheng, L.-M. Onedimensional copper phosphonates containing $\mu$-halide, $\mu$-pyridyl $N$ oxide and phosphonate bridging ligands. Inorg. Chim. Acta 2007, 360, 4117-4124.

(31) Zhang, W.; Chen, L.-Z.; Xiong, R.-G.; Nakamura, T.; Huang, S. D. New Ferroelectrics Based on Divalent Metal Ion Alum. J. Am. Chem. Soc. 2009, 131, 12544-12545.

(32) Hajlaoui, F.; Naili, H.; Yahyaoui, S.; Mhiri, T.; Bataille, T. Crystal structures of two enantiomorphous 2-ethylpiperazinediium hexaaquacopper sulfates $\left[(\mathrm{R}\right.$ or S $\left.)-\mathrm{C}_{5} \mathrm{H}_{14} \mathrm{~N}_{2}\right]\left[\mathrm{Cu}\left(\mathrm{H}_{2} \mathrm{O}\right)_{6}\right]\left(\mathrm{SO}_{4}\right)_{2}$. J. Struct. Chem. 2012, 53, 334-340.

(33) An, H.; Wang, L.; Hu, Y.; Xu, T.; Hou, Y. Spontaneous Resolution of Evans-Showell-Type Polyoxometalates in Constructing Chiral Inorganic-Organic Hybrid Architectures. Inorg. Chem. 2016, 55, 144-153.

(34) Persson, I.; Persson, P.; Sandström, M.; Ullström, A.-S. Structure of Jahn-Teller Distorted Solvated Copper(II) Ions in Solution, and in Solids with Apparently Regular Octahedral Coordination Geometry. J. Chem. Soc., Dalton Trans. 2002, 12561265 and references therein.

(35) Abbasi, A.; Lindqvist-Reis, P.; Eriksson, L.; Sandström, D.; Lidin, S.; Persson, I.; Sandström, M. Highly Hydrated Cations: Deficiency, Mobility, and Coordination of Water in Crystalline Nonahydrated Scandium(III), Yttrium(III) and Lanthanoid(III) Trifluoromethanesulfonates. Chem. - Eur. J. 2005, 11, 4065-4077.

(36) Persson, I.; D’Angelo, P.; De Panfilis, S.; Sandström, M.; Eriksson, L. Hydration of the Lanthanoid(III) Ions in Aqueous Solution and Crystalline Hydrates Studied by EXAFS Spectroscopy and Crystallography. The Myth of the "Gadolinium Break". Chem. Eur. J. 2008, 14, 3056-3066.

(37) Bondi, A. van der Waals Volumes and Radii. J. Phys. Chem. 1964, 68, 441-452.

(38) Ozutsumi, K.; Abe, Y.; Takahashi, R.; Ishiguro, S.-i. Chloro and bromo complexation of the manganese(II) ion and solvation structure of the manganese(II), iron(II), cobalt(II), nickel(II), copper(II), and zinc(II) ions in hexamethylphosphoric triamide. J. Phys. Chem. 1994, 98, 9894-9899.

(39) Klementiev, K.; Norén, K.; Carlson, S.; Sigfridsson Clauss, K. G. V.; Persson, I. The BALDER beam-line at the MAX IV Laboratory. J. Phys.: Conf. Ser. 2016, 712, 012023.
(40) Avila-Abellan, J.; Broseta, M.; Cuni, G.; Matilla, O.; Rodriguez, M.; Ruz, A.; Salabert, J.; Serra-Gallifa, X.; Milan-Otero, A.; Sjöblom, P. Em\# Electrometer Comes to Light. Proceedings of the 16th International conference on Accelerator and Large Experimental Physics Control System, Barcelona, Spain, 2017, pp 137-142. DOI: 10.18429/JACoW-ICALEPCS2017-TUAPL04.

(41) https://www.ohwr.org/project/pandabox/wikis/home, downloaded January 31, 2020.

(42) Mesu, J. G.; van der Eerden, A. M. J.; de Groot, F. M. F.; Weckhuysen, B. M. Synchrotron Radiation Effects on Catalytic Systems As Probed with a Combined In-Situ UV-Vis/XAFS Spectroscopic Setup. J. Phys. Chem. B 2005, 109, 4042-4047.

(43) Thompson, A.; Attwood, D.; Gullikson, E.; Howells, M.; Kim, K.-J.; Kirz, J.; Lindau, I.; Liu, Y.; Pianetta, P.; Robinson, A.; Scofield, J.; Underwood, J.; Vaughan, D.; Williams, G.; Winick, H. X-ray data booklet, 3rd rev.; Lawrence Berkeley National Laboratory: Berkeley, CA, 2009.

(44) George, G. N.; Pickering, I. J. EXAFSPAK-A suite of computer programs for analysis of X-ray absorption spectra, 2000.

(45) Calvin, S. XAFS for Everyone; CRC Press: 2013; ISBN 9781439878637.

(46) Zabinsky, S. I.; Rehr, J. J.; Ankudinov, A. Multiple Scattering Calculations of X-ray Absorption Spectra. Phys. Rev. B: Condens. Matter Mater. Phys. 1995, 52, 2995-3009.

(47) Johansson, G. An X-Ray Investigation of the Structure of the $\mathrm{Hg}_{2}{ }^{2++}$ Ion in Solution. Acta Chem. Scand. 1966, 20, 553-562.

(48) Johansson, G. An X-Ray Investigation of the Hydrolysis Products of Mercury(II) in Solution. Acta Chem. Scand. 1971, 25, 2787-2798.

(49) Stålhandske, C. M. V.; Persson, I.; Sandström, M.; KamienskaPiotrowicz, E. A Large Angle Scattering and Vibrational Spectroscopic Study of the Solvated Zinc, Cadmium and Mercury(II) Ions in N, NDimethylthioformamide Solution. Inorg. Chem. 1997, 36, 3174-3182.

(50) Johansson, G.; Sandström, M. Computer Programs for the Analysis of Data on X-ray Diffraction by Liquids. Chem. Scr. 1973, 4, 195-198.

(51) Molund, M.; Persson, I. STEPLR-A Program for Refinements of Data on X-Ray Scattering by Liquids. Chem. Scr. 1985, 25, 197197.

(52) Sheldrick, G. M. SHELX 2016/6: Program for Crystal Structure Refinement; University of Göttingen, Göttingen, Germany, 2014.

(53) Morosin, B. The crystal structure of $\mathrm{Cu}\left(\mathrm{NO}_{3}\right)_{2}\left(\mathrm{H}_{2} \mathrm{O}\right)_{2.5}$. Acta Crystallogr., Sect. B: Struct. Crystallogr. Cryst. Chem. 1970, 26, 12031208.

(54) Garaj, J. The crystal structure of $\mathrm{Cu}\left(\mathrm{NO}_{3}\right)_{2} *\left(\mathrm{H}_{2} \mathrm{O}\right)_{2.5}$. Acta Chem. Scand. 1968, 22, 1710-1711.

(55) Garaj, J.; Gazo, J. Nitrate group as ligand in solid copper(II) complexes. The structure of $\mathrm{Cu}\left(\mathrm{NO}_{3}\right)_{2}\left(\mathrm{H}_{2} \mathrm{O}\right)_{2.5}$. Chem. Zvesti 1969, 23, 829-842.

(56) Gallucci, J. C.; Gerkin, R. E. Structure of copper(II) perchlorate hexahydrate. Acta Crystallogr., Sect. C: Cryst. Struct. Commun. 1989, $45,1279-1284$.

(57) Mani, N. V.; Ramaseshan, S. The crystal structure of copper perchlorate hexahydrate, $\mathrm{Cu}\left(\mathrm{ClO}_{4}\right)_{2} \bullet 6 \mathrm{H}_{2} \mathrm{O} \mathrm{Z}$. Kristallogr. 1961, 115, 97-109.

(58) Li, X.-H.; Xia, F.-Y.; Xiao, H.-P.; Hu, M.-L. Hexaaquacopper(II) diperchlorate dehydrate. Acta Crystallogr., Sect. E: Struct. Rep. Online 2004, 60, i31-i32.

(59) Blackburn, A. C.; Gallucci, J. C.; Gerkin, R. E. Structure of hexaaquacopper(II) bromate. Acta Crystallogr., Sect. C: Cryst. Struct. Commun. 1991, 47, 2019-2023.

(60) Ray, S.; Zalkin, A.; Templeton, D. H. Crystal structure of copper fluorosilicate hexahydrate. Acta Crystallogr., Sect. B: Struct. Crystallogr. Cryst. Chem. 1973, 29, 2748-2751.

(61) Iskhakova, L. D.; Trunov, V. K.; Shchegoleva, T. M.; Ilyukhin, V. V.; Vedernikov, A. A. Crystal structure of chalcanthite $\mathrm{Cu}\left(\mathrm{SO}_{4}\right)$. $5 \mathrm{H}_{2} \mathrm{O}$ grown under microgravity. Kristallografiya 1983, 28, 651-657. 
(62) Varghese, J. N.; Maslen, E. N. Electron density in non-ideal metal complexes. I. Copper sulphate pentahydrate. Acta Crystallogr., Sect. B: Struct. Sci. 1985, 41, 184-190.

(63) Ting, V. P.; Henry, P. F.; Schmidtmann, M.; Wilson, C. C.; Weller, M. T. In situ neutron powder diffraction and structure determination in controlled humidities. Chem. Commun. 2009, 75277529.

(64) Bacon, G. E.; Titterton, D. H. Neutron-diffraction studies of $\mathrm{CuSO}_{4} \cdot 5 \mathrm{H}_{2} \mathrm{O}$ and $\mathrm{CuSO}_{4} \cdot 5 \mathrm{D}_{2} \mathrm{O}$. Z. Kristallogr. 1975, 141, 330-341. (65) Beevers, C. A.; Lipson, H. Crystal structure of coppersulfate pentahydrate $\mathrm{CuSO}_{4}\left(\mathrm{H}_{2} \mathrm{O}\right)_{5}$. Proc. Royal Soc. London, Ser. A 1934, 146, 570-582.

(66) Bacon, G. E.; Curry, N. A. The water molecules in $\mathrm{CuSO}_{4}\left(\mathrm{H}_{2} \mathrm{O}\right)_{5}$. Proc. Royal Soc. London, Ser. A 1962, 266, 95-108.

(67) Chen, S.-C.; Qin, J.; Zhang, Z.-H.; Hu, M.; Sun, F.-A.; Liu, L.; He, M.-Y.; Chen, Q. Influence of solvent on the structures of two copper(II) coordination polymers with tetraiodoterephthalate: syntheses, crystal structures, and properties. J. Coord. Chem. 2013, 66, 1924-1932.

(68) Dorn, T.; Chamayou, A.-C.; Janiak, C. Hydrophilic interior between hydrophobic regions in inverse bilayer structures of cation1,1'-binaphthalene-2,2'-diyl phosphate salts. New J. Chem. 2006, 30, 156.

(69) Saxena, P.; Mandal, S. K.; Sharma, K.; Murugavel, R. Delineating factors that dictate the framework of a bulky phosphate derived metal complexes: Sterics of phosphate, anion of the metal salt and auxiliary N-donor ligand. Inorg. Chim. Acta 2018, 469, 353-365.

(70) Peng, Y.-H.; Li, Y.-J.; Li, C.-H.; Hu, L.; Zuo, J.-L.; You, X.-Z. Syntheses, structures, and properties of tricarbonyl rhenium(I) heteronuclear complexes with the multidentate bridging ligand containing bis(2-pyridine) and carboxylic acid. Inorg. Chim. Acta 2010, 363, 3742-3749.

(71) Bai, Y.; Zheng, G.-S.; Dang, D.-B.; Gao, H.; Qi, Z.-Y.; Niu, J.-Y. A one-dimensional polyoxometalate-based polymer $\left[\mathrm{Cu}(\mathrm{DMF})_{6}\right]$ $\left[\mathrm{PMo}^{\mathrm{V}} \mathrm{Mo}^{\mathrm{VI}}{ }_{11} \mathrm{O}_{40} \mathrm{Cu}(\mathrm{DMF})_{4}\right] \cdot \mathrm{DMF}$ : Crystal structure and luminescent properties. Spectrochim. Acta, Part A 2010, 77, 727-731.

(72) White, J. M.; McInnis, L.; Donnelly, P. S. CCDC code 1036000, 2014. See ref 4

(73) Olmstead, M. M.; Marlin, D. S.; Mascharak, P. K. CCDC code 1053817, 2015. See ref 4

(74) Wang, Y.; Li, F.; Xu, L.; Jiang, N.; Liu, X. Multidimensional crystal frameworks based on heteropoly blue building block of $\left[\mathrm{SiW}_{10} \mathrm{Mo}_{2}{ }_{2} \mathrm{O}_{40}\right]^{6-}$ : synthesis, structures and magnetic properties. Dalton Trans. 2013, 42, 5839-5847.

(75) Wang, Y.; Xu, L.; Jiang, N.; Zhao, L.; Li, F.; Liu, X. Multidimensional frameworks constructed from Keggin-type heteropoly blue of molybdenum-tungsten cluster. CrystEngComm 2011, 13, 410-413.

(76) Ji, S.-J.; Yu, H.; Lang, J.-P. Synthesis and Structural Characterization of $\left[\mathrm{Cu}(\mathrm{DMF})_{6}\right]\left[\left(\eta_{5}-\mathrm{C}_{5} \mathrm{Me}_{5}\right) \mathrm{WS}_{3}(\mathrm{CuBr})_{3}\right]_{2} \cdot \mathrm{Et}_{2} \mathrm{O}$ Jiegou. Huaxue 2002, 21, 26-30.

(77) Lemoine, P.; Herpin, P. Structure de tétrakis $(N, N$ diméthylacétamide)diperchloratocuivre(II) à $143 \mathrm{~K}$. Acta Crystallogr., Sect. B: Struct. Crystallogr. Cryst. Chem. 1980, 36, 2772-2774. 